\title{
Lineage-specific events underlie aortic root aneurysm pathogenesis in Loeys-Dietz syndrome
}

\author{
Elena Gallo MacFarlane, ${ }^{1,2}$ Sarah J. Parker, ${ }^{1,3}$ Joseph Y. Shin, ${ }^{4}$ Benjamin E. Kang, ${ }^{1}$ Shira G. Ziegler, ${ }^{4}$ Tyler J. Creamer, ${ }^{2,4}$ \\ Rustam Bagirzadeh, ${ }^{1,2}$ Djahida Bedja, ${ }^{3}$ Yichun Chen, ${ }^{1}$ Juan F. Calderon, ${ }^{4}$ Katherine Weissler, ${ }^{5}$ Pamela A. Frischmeyer-Guerrerio, ${ }^{5}$ \\ Mark E. Lindsay, ${ }^{1,6}$ Jennifer P. Habashi, ${ }^{1,6}$ and Harry C. Dietz ${ }^{1,7}$ \\ 1McKusick-Nathans Institute of Genetic Medicine, ${ }^{2}$ Department of Surgery, ${ }^{3}$ Division of Cardiology, and ${ }^{4}$ McKusick-Nathans Institute of Cenetic Medicine, Human Genetics Program, Johns Hopkins University \\ School of Medicine, Baltimore, Maryland, USA. '5aboratory of Allergic Diseases, National Institute of Allergy and Infectious Diseases, NIH, Bethesda, Maryland, USA. 'Division of Pediatric Cardiology, \\ Department of Pediatrics, Johns Hopkins University School of Medicine, Baltimore, Maryland, USA. 'Howard Hughes Medical Institute, Bethesda, Maryland, USA.
}

\begin{abstract}
The aortic root is the predominant site for development of aneurysm caused by heterozygous loss-of-function mutations in positive effectors of the transforming growth factor- $\beta$ (TCF- $\beta$ ) pathway. Using a mouse model of Loeys-Dietz syndrome (LDS) that carries a heterozygous kinase-inactivating mutation in TCF- $\beta$ receptor I, we found that the effects of this mutation depend on the lineage of origin of vascular smooth muscle cells (VSMCs). Secondary heart field-derived (SHF-derived), but not neighboring cardiac neural crest-derived (CNC-derived), VSMCs showed impaired Smad2/3 activation in response to TGF- $\beta$, increased expression of angiotensin II (AngII) type 1 receptor (Agtr1a), enhanced responsiveness to AngII, and higher expression of TGF- $\beta$ ligands. The preserved TGF- $\beta$ signaling potential in CNC-derived VSMCs associated, in vivo, with increased Smad2/3 phosphorylation. CNC-, but not SHF-specific, deletion of Smad2 preserved aortic wall architecture and reduced aortic dilation in this mouse model of LDS. Taken together, these data suggest that aortic root aneurysm predisposition in this LDS mouse model depends both on defective Smad signaling in SHF-derived VSMCs and excessive Smad signaling in CNC-derived VSMCs. This work highlights the importance of considering the regional microenvironment and specifically lineage-dependent variation in the vulnerability to mutations in the development and testing of pathogenic models for aortic aneurysm.
\end{abstract}

\section{Introduction}

Aneurysms are focal dilatations in the wall of an artery that are often asymptomatic until dissection (tear) or rupture occurs (1, 2). Thoracic aortic aneurysms occur in all age groups (including young children), have a strong genetic basis, and often develop in individuals affected by hereditary connective tissue disorders (2-4). Very few pharmacological therapies exist, and the only proven treatment option to prevent rupture is surgical repair $(5$, 6 ). Binding of transforming growth factor- $\beta$ (TGF- $\beta$ ) ligand to tetrameric receptor complexes composed of 2 type I (T $\beta \mathrm{RI})$ and 2 type II (T $\beta$ RII) subunits, which are encoded by the TGFBR1 and TGFBR2 genes, respectively (7), induces receptor-mediated phosphorylation of intracellular signaling mediators Smad2 and Smad3 (mothers against decapentaplegic homolog 2 and 3) at the C-terminal Ser-X-Ser motif; binding of phosphorylated Smad2 and Smad3 (p-Smad2/3) to Smad4 induces translocation of this complex to the nucleus, and transcription of TGF- $\beta$ target genes in concert with other transcription and chromatin remodeling factors $(8,9)$. Binding of TGF- $\beta$ to its receptors can also activate

Conflict of interest: The authors have declared that no conflict of interest exists. License: Copyright 2019, American Society for Clinical Investigation.

Submitted: July 13, 2018; Accepted: November 15, 2018.

Reference information: J Clin Invest. 2019;129(2):659-675.

https://doi.org/10.1172/JCl123547.
Smad-independent pathways, although the specific pathways activated and their temporal dynamics vary depending on cell type $(10,11)$. Heterozygous kinase-inactivating mutations in genes coding for either TGF- $\beta$ receptor subunit (TGFBR1 or TGFBR2) cause LDS, a syndrome characterized by a highly penetrant and aggressive aneurysmal disease (12). LDS can also be caused by heterozygous loss-of-function mutations in genes encoding TGF- $\beta$ ligands (TGFB2 and TGFB3) or intracellular signaling mediators (SMAD2 or SMAD3) (12-18). In patients and in mouse models of LDS, the aortic root represents the site of greatest predisposition to dilation $(2,6,12-14,16,19)$. Although the mutational repertoire associated with LDS seemingly implicates defective Smad signaling as the primary driver of disease, evidence for increased Smad2/3 phosphorylation is observed in aortic tissue derived from LDS patients and mouse models (12-14,16,19-21), suggesting that compensatory mechanisms might contribute to disease, and generating ambiguity regarding the precise role of Smad signaling in pathogenesis (22-24). Evidence from the literature indicates that the embryological origin of VSMCs can influence their signaling response to extracellular cues, including those mediated by TGF- $\beta$ (25-29). In this study, we examine the effect of an LDS-causing mutation on the signaling capacity of the 2 types of VSMCs that populate the aortic media of the proximal aorta, namely SHF- and CNC-derived VSMCs $(30,31)$, and assess how lineage-specific effects influence aortic disease. 
A

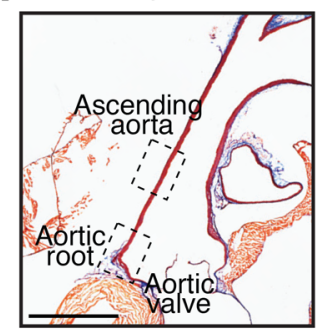

C

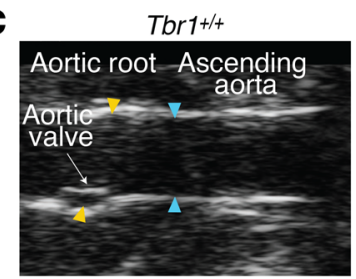

Tbr1MR/t

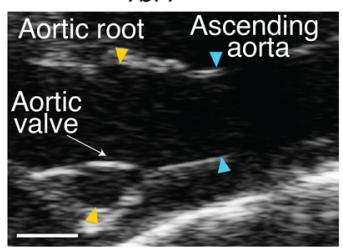

Tbr1MR/t

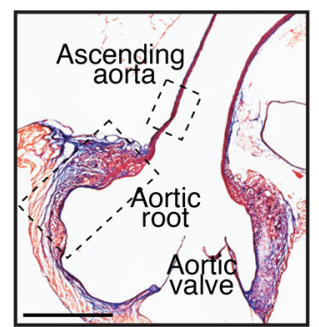

D
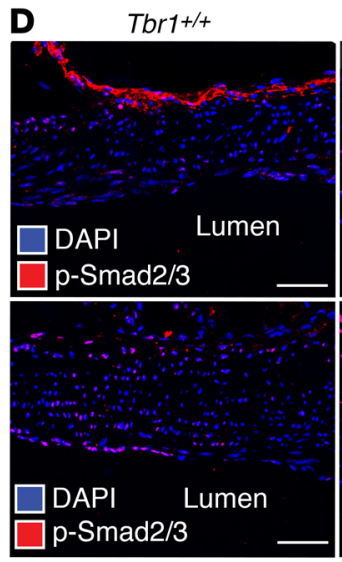

B
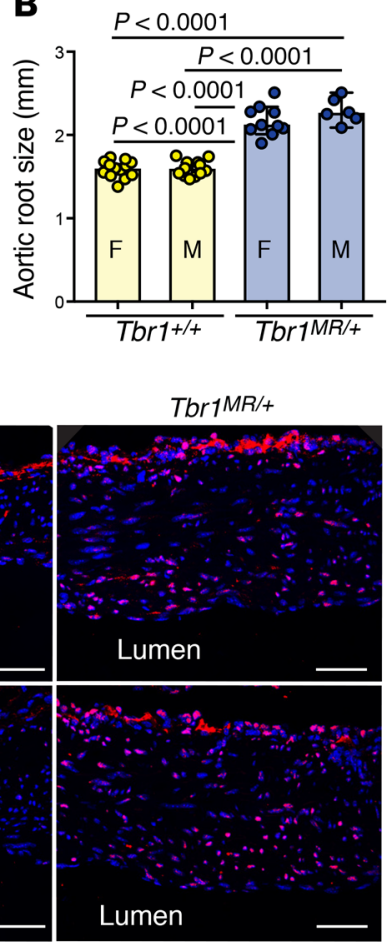

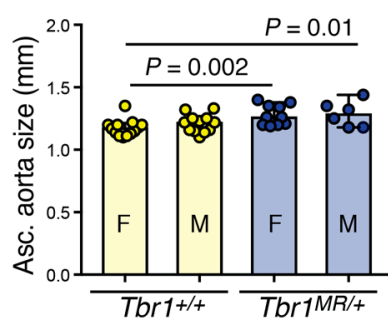

E $\quad T b r^{+/+}$
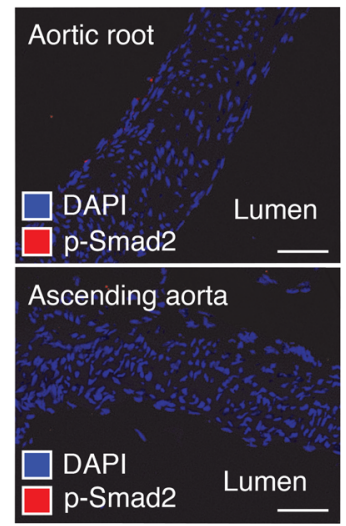

ToryMR/+

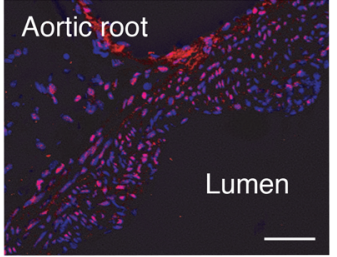

Ascending aorta
$\mathbf{F}$
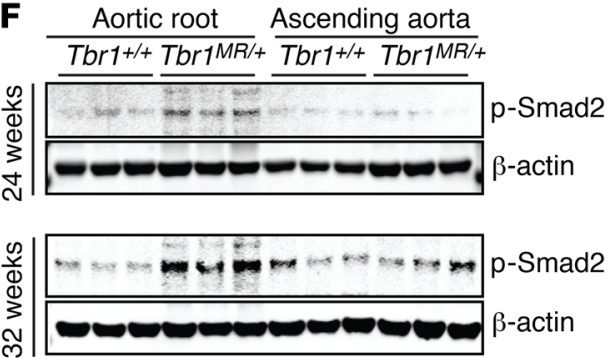

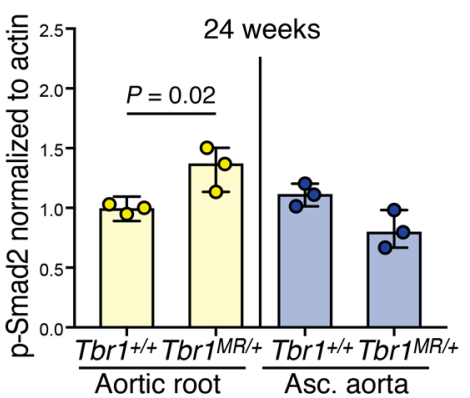

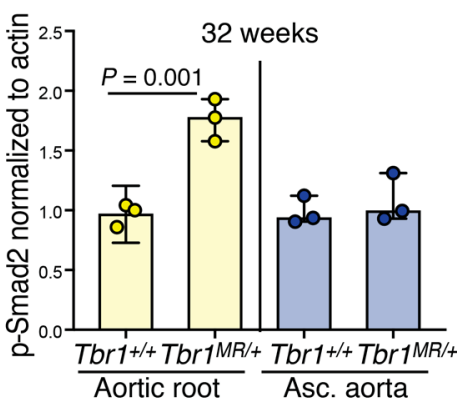

Figure 1. Tbr $^{\mathrm{MR} /+}$ mice develop dilation of the aortic root in association with localized increase in Smad2/3 phosphorylation. (A) Masson's trichrome staining of the proximal aorta of control $\left(\mathrm{Tbr}^{+/+}\right)$and mutant $\left(\mathrm{Tbr}^{\mathrm{MR} /+}\right)$ mice at 20 weeks of age. Scale bars: 1,000 $\mu \mathrm{m}$. The dashed rectangles indicate the areas used for in situ analyses. (B) Aortic diameters of mice of the indicated genotypes at 16 weeks of age. F, females $\left(n=13\right.$ for Tbr $7^{+/+}$and $n=10$ for $\operatorname{Tbr}^{\mathrm{MR/+})}$ ) M, males $\left(n=12\right.$ for $\mathrm{Tbr}^{+/+} ; n=6$ for $\left.\mathrm{Tbr}^{\mathrm{MR} /+}\right)$. No sex-specific differences were observed within any experimental group. $P$ values refer to Kruskal-Wallis test with FDR-based multiple comparison correction. (C) Representative parasternal long-axis echocardiographic view showing the boundaries from which measurements were taken for aortic root (yellow arrows) and ascending aorta (blue arrows). (D) Representative immunofluorescence (IF) images of the aortic root of 16-week-old mice of the indicated genotypes probed with an anti-p-Smad2 or an unrelated anti-p-Smad2/3 antibody. Scale bars: 50 $\mu \mathrm{m}$. Image enhancement for visual display was applied uniformly to all panels. Experiment was conducted at least 3 times. (E) Representative IF images of the aortic root and ascending aorta of 12-week-old mice probed with an anti-p-Smad2 antibody. Scale bars: $50 \mu \mathrm{m}$. Image enhancement for visual display was applied uniformly to all panels. Experiment was conducted at least 3 times. (F) Immunoblot of protein lysates from the aortic root and ascending aorta of mice of the indicated genotypes at 24 and 32 weeks of age after probing with antibodies that recognize $p$-Smad2 and $\beta$-actin ( $n=3$ ). Quantification of $\mathrm{p}$-Smad2 after normalization to $\beta$-actin is shown on the right. $P$ values refer to 1-way ANOVA followed by Holm-Sidak's multiple comparisons test. Numerical data are presented as scatter dot-plots with boxes, with the box denoting the mean; error bars identify the $95 \%$ confidence interval.

\section{Results}

Tgfbr $1^{\text {M318R/+ }}$ mice develop aortic root dilation in association with localized increase in Smad2/3 phosphorylation and TGF- $\beta$ ligand expression. We previously generated and described a mouse model of LDS carrying a heterozygous kinase-inactivating missense mutation in $\operatorname{Tgfbr1}\left(\mathrm{Tgfbr}^{\mathrm{M} 318 R /}\right.$, , referred to herein as $\left.\mathrm{Tbr}^{\mathrm{MR} /+}\right)$; this mutation is equivalent to a TGFBR1 mutation found in LDS patients that results in a methionine to arginine substitution at amino acid $318(12,19)$. Both female and male $\operatorname{Tbrr}^{\mathrm{MR} /+}$ mice develop dilation of the aortic root with rapid tapering in the more distal ascending aorta (Figure 1, A-C, and ref. 19). Although this heterozygous mutation is expected to result in loss of kinase activity in approximately half of TGF- $\beta$ receptor complexes (32), and thus diminished levels of $\mathrm{p}-\mathrm{Smad} 2 / 3$, in situ techniques detect increased levels of $\mathrm{p}-\mathrm{Smad} 2 / 3$ in the aortic root media by 12-16 weeks of age (Figure 1, D and E, and ref. 19), while averaging methods such as immunoblots document the same finding by 24-32 weeks of age (Figure 1F and ref. 19). Notably, increased lev- 
A
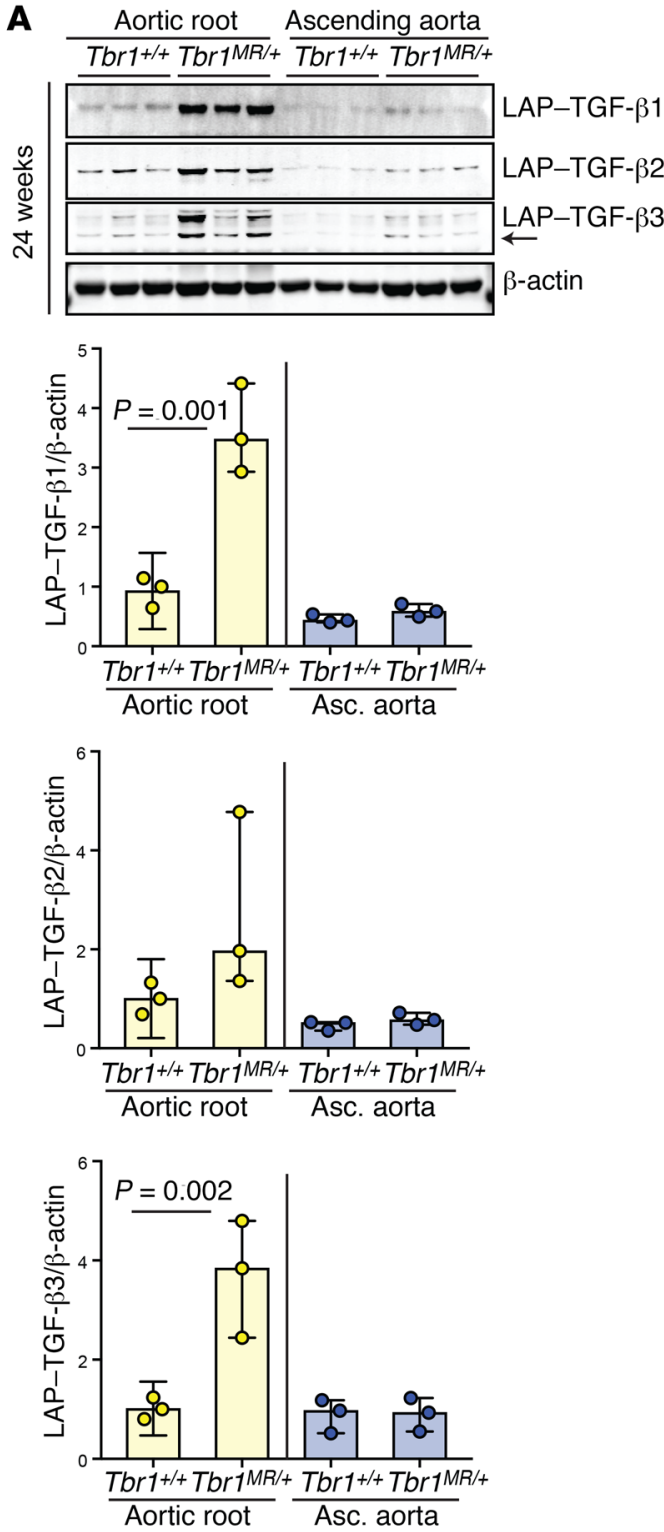

B
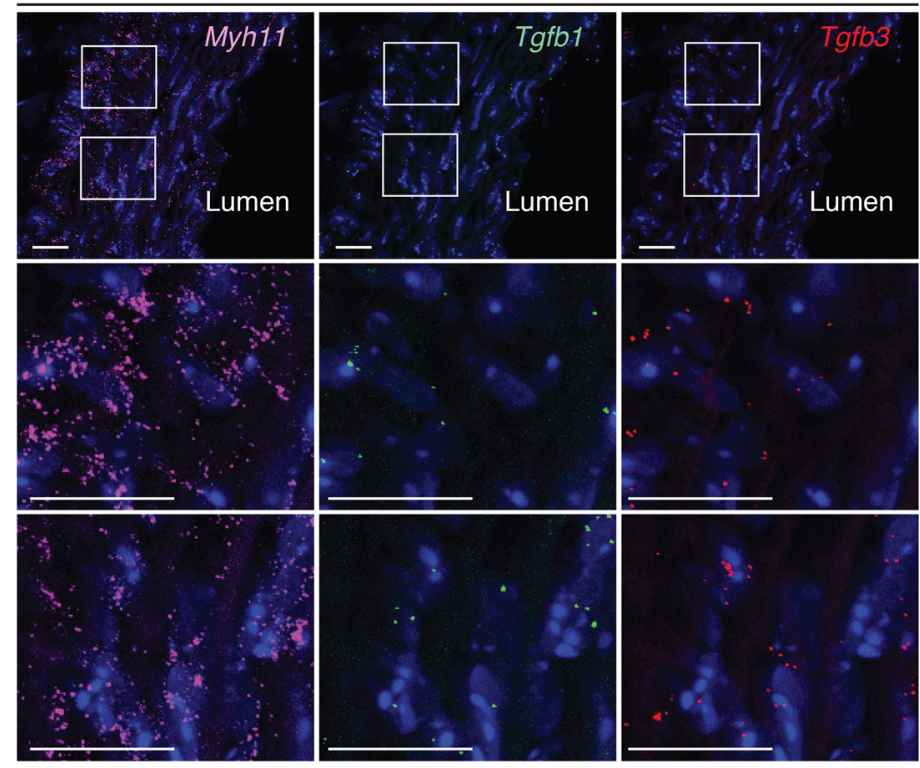

Tbr1MR/t

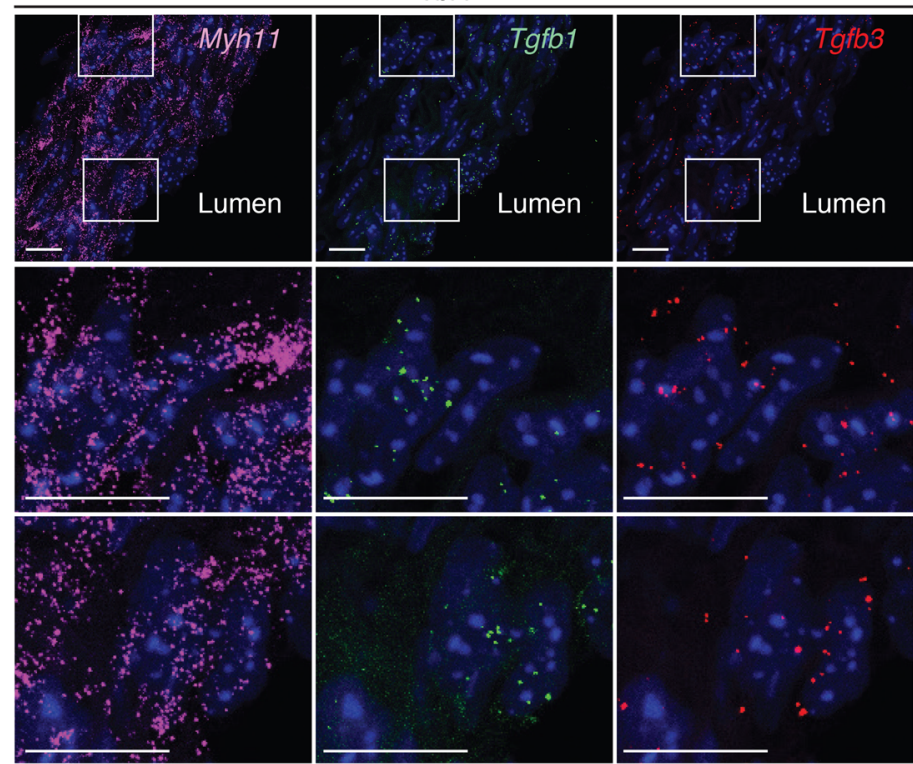

Figure 2. Tbr ${ }^{M R /+}$ mice develop dilation of the aortic root in association with localized increase in TGF- $\beta 1$ and TGF- $\beta 3$ ligand expression. (A) Immunoblot of lysates of the aortic root and ascending aorta of mice of the indicated genotypes at 24 weeks of age after probing with antibodies that recognize full-length latency-associated peptide (LAP)-TGF- $\beta 1$, LAP-TGF- $\beta 2$, LAP-TGF- $\beta 3$; arrow identifies the band quantified for LAP-TGF- $\beta 3$. Quantification after normalization to $\beta$-actin (same as that shown in in Figure 1F) is shown below $(n=3)$. $P$ values refer to 1-way ANOVA followed by Holm-Sidak's multiple comparisons test. (B) Representative RNA in situ hybridization of the aortic root of 24-week-old mice using RNAscope probes directed against the smooth muscle-specific transcript Myh11, and against Tgfb1 and Tgfb3; insets mark the area shown at higher magnification for each panel. Scale bars: $20 \mu \mathrm{m}$. Experiment was conducted at least 3 times. Image enhancement for visual display was applied uniformly to all panels. Numerical data are presented as scatter dot-plots with boxes, with the box denoting the mean; error bars identify the $95 \%$ confidence interval.

els of $\mathrm{p}-\mathrm{Smad} 2 / 3$ colocalize with the site of dilation, and become more pronounced as disease progresses (Figure $1, \mathrm{E}$ and $\mathrm{F}$ ). The localized increase in $\mathrm{p}-\mathrm{Smad} 2 / 3$ levels in the aortic root associates with increased levels of TGF- $\beta 1$ and TGF- $\beta 3$ ligand (Figure $2 \mathrm{~A}$ ), suggesting that overexpression of TGF- $\beta$ might contribute to the apparent increase in signaling at this location. While adventitial fibroblasts and recruited immune cells likely contribute to the increased levels of TGF- $\beta$ ligand assessed by immunoblot, increased expression of $T g f b 1$ and $T g f b 3$ can also be detected in the aortic root media of $T b r 1^{M R /+}$ mice in cells that also express the VSMC-specific transcript Myh11 (Figure 2B).

Defective induction of Smad-dependent pathways in response to TGF- $\beta$ in SHF-, but not CNC-derived, VSMCs generated from Tbr $1^{M R /+}$ mice. We next examined the cell-autonomous signaling consequences of the $T b r 1^{M R /+}$ mutation in SHF- and CNCderived VSMCs $(30,31)$ (Figure 3A). VSMCs derived from these 
A

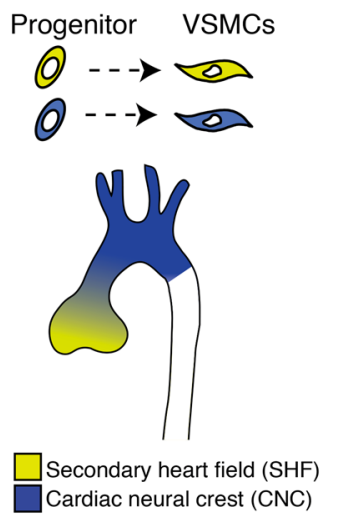

B

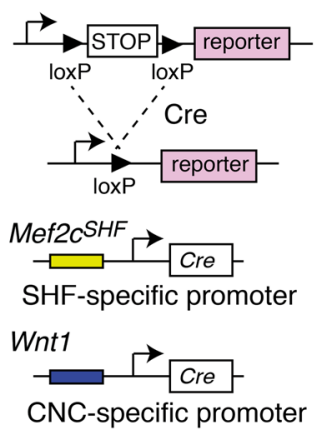

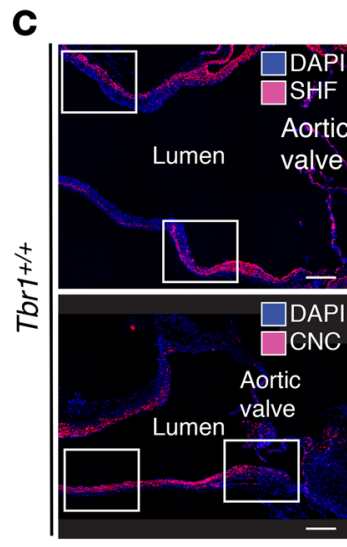

Ascending aorta
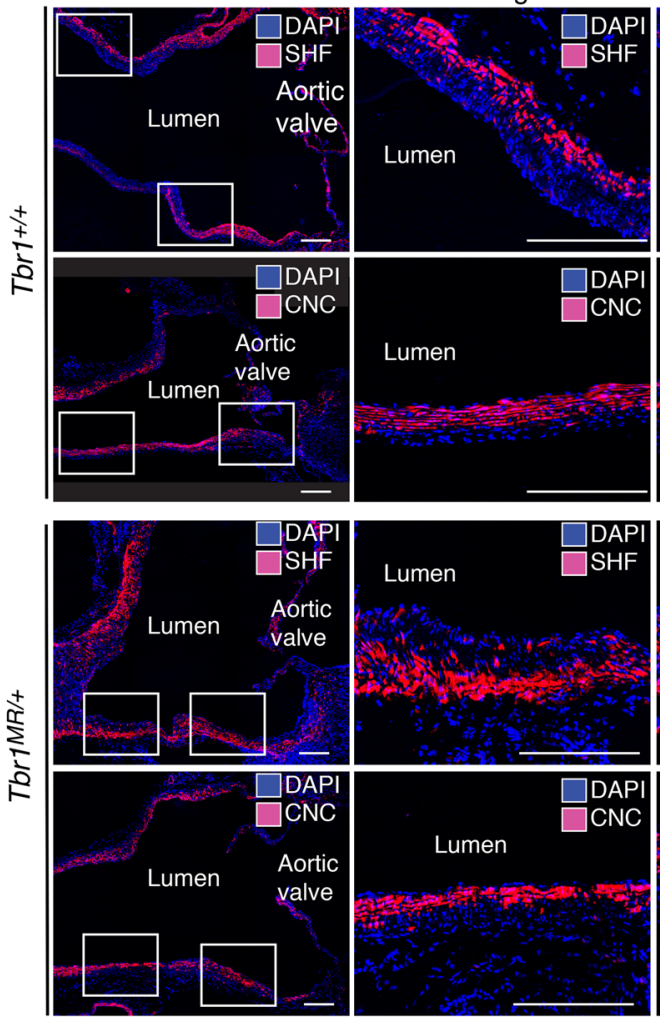

Aortic root
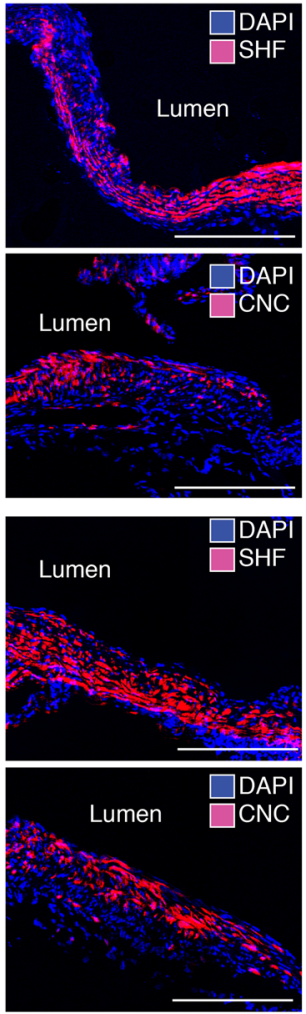

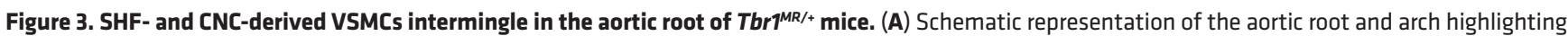
the embryonic origin of VSMCs that populate the medial layer in these regions. (B) Schematic representation of mouse transgenic lines used for tracing of SHF- and CNC-derived VSMCs. Mice carrying a conditional STOP cassette controlling expression of a fluorescent reporter were crossed to mice that express the Cre recombinase under the control of the SHF-specific promoter Mef2 $c^{5 H F}$ or CNC-specific promoter Wnt1. Removal of the STOP cassette induces expression of the fluorescent reporter and allows identification of VSMCs derived from the lineage of interest even after these promoters are silenced postnatally. (C) Representative fluorescence images of the aorta of control ( $\left.\mathrm{Tbr}^{+/+}\right)$and mutant ( $\left.\mathrm{Tbr} \mathrm{TR}^{\mathrm{M} /+}\right)$ mice in which SHF- and CNC-derived cells are lineage-traced based on TdTomato fluorescence; insets mark the areas in the ascending aorta and aortic root shown at higher magnification to the right of each panel. SHF- and CNC-derived VSMCs intermingle in the aortic root, with relative polarization towards the adventitial and luminal margins of the media, respectively. Scale bars: $200 \mu \mathrm{m}$. Image enhancement for visual display was applied uniformly to all panels. Experiment was conducted at least 3 times.

2 lineages were identified using conditional fluorescent reporter alleles and transgenic mice that express $\mathrm{Cre}$ recombinase under the control of SHF-specific ( $\left.M e f 2 c^{S H F}-C r e\right)$ (33) or CNC-specific (Wnt1-Cre) $(34,35)$ promoters, thus circumventing the lack of lineage-specific postnatal markers (Figure 3B). SHF- and CNC-derived VSMCs intermingle in the aortic root, with relative polarization towards the adventitial and luminal margins of the media, respectively (Figure 3C and ref. 36). We generated primary VSMCs from the aortic root of lineage-traced 8-weekold $T b r 1^{M R /+}$ and control mice, and used fluorescence-activated cell sorting (FACS) to isolate SHF-derived and CNC-derived VSMCs based on expression of the lineage-specific fluorescent reporter. VSMCs from both lineages and genotypes expressed similar amounts of the VSMC-specific marker smooth muscle myosin heavy chain (SMMHC) and showed similar proliferation rates (Supplemental Figure 1, A and B; supplemental material available online with this article; https://doi.org/10.1172/ JCI123547DS1). SHF- and CNC-derived VSMCs from control $\left(\mathrm{Tbr}^{+/+}\right)$and mutant $\left(\mathrm{Tbr} \mathrm{1}^{\mathrm{MR} /+}\right)$ mice were assessed for their ability to phosphorylate $\mathrm{Smad} 2$ and $\mathrm{Smad} 3$ in response to exogenous TGF- $\beta$ ligand both by phospho-flow cytometry, using an antibody able to recognize both $\mathrm{p}-\mathrm{Smad} 2$ and $\mathrm{p}-\mathrm{Smad} 3$ (p-Smad2/3) (Figure 4A) and by immunoblot using antip-Smad 2 and anti-p-Smad3 antibodies separately (Figure 4B). In both assays, SHF-derived $T b r 1^{M R /+}$ VSMCs showed decreased $\mathrm{p}-\mathrm{Smad} 2 / 3$ induction in response to TGF- $\beta$. In contrast, CNC-derived VSMCs from $T b r 1^{M R /+}$ mice showed a signaling response comparable to that of those from $\mathrm{Tbr}^{+/+}$control animals (Figure 4, A and B, and Supplemental Figure 1C). TGF- $\beta$ dependent induction of Smad-independent pathways, such as phosphorylation of Akt at serine 473 (37) or phosphorylation of extracellular signal-regulated kinase (p-ERK) at threonine 202 and tyrosine 204 (38), was negligible and not significantly different between lineages or genotypes (Supplemental Figure 2 , A and B). Defective TGF- $\beta$ responsiveness in SHF-derived VSMCs from $T b r 1^{M R /+}$ mice correlated with decreased induction of the TGF- $\beta$ target genes Ctgf and Serpine1; no difference was observed between control and mutant CNC-derived VSMCs (Figure 4C). These data suggest that defective signaling in Tbr $1^{\text {MR/+ }}$ SHF-derived VSMCs may be critical to predisposition to dilation in the aortic root, where they predominate (36). Analysis of $\mathrm{p}-\mathrm{Smad} 2 / 3$ induction in response to TGF- $\beta$ in other 

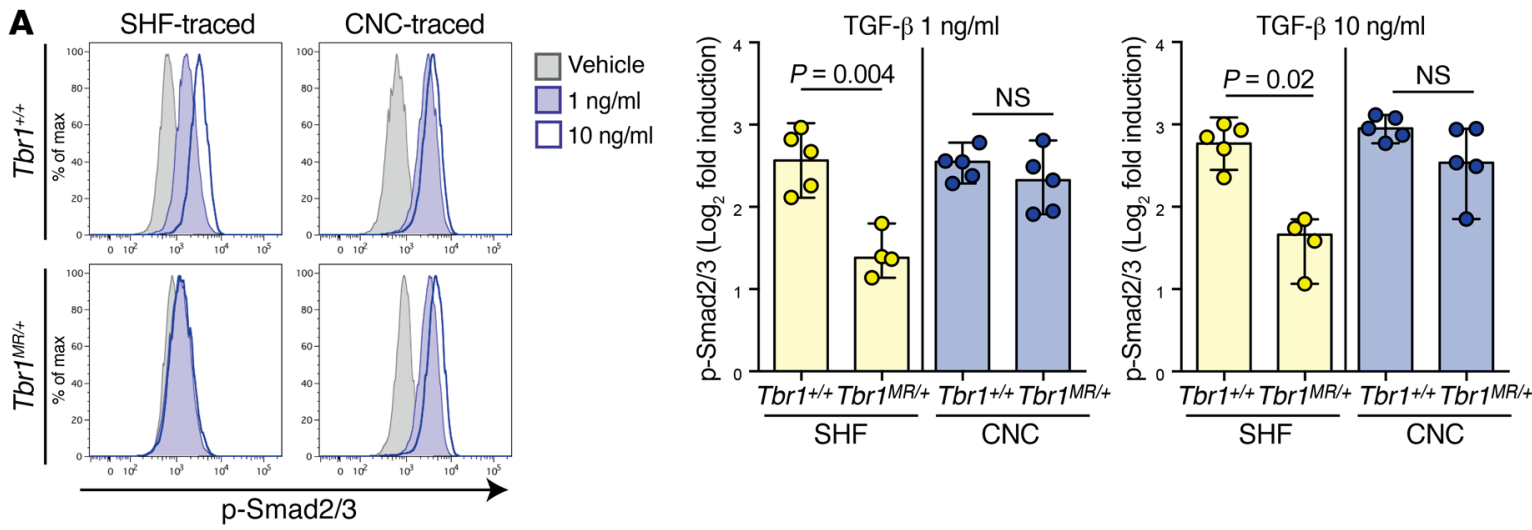

B
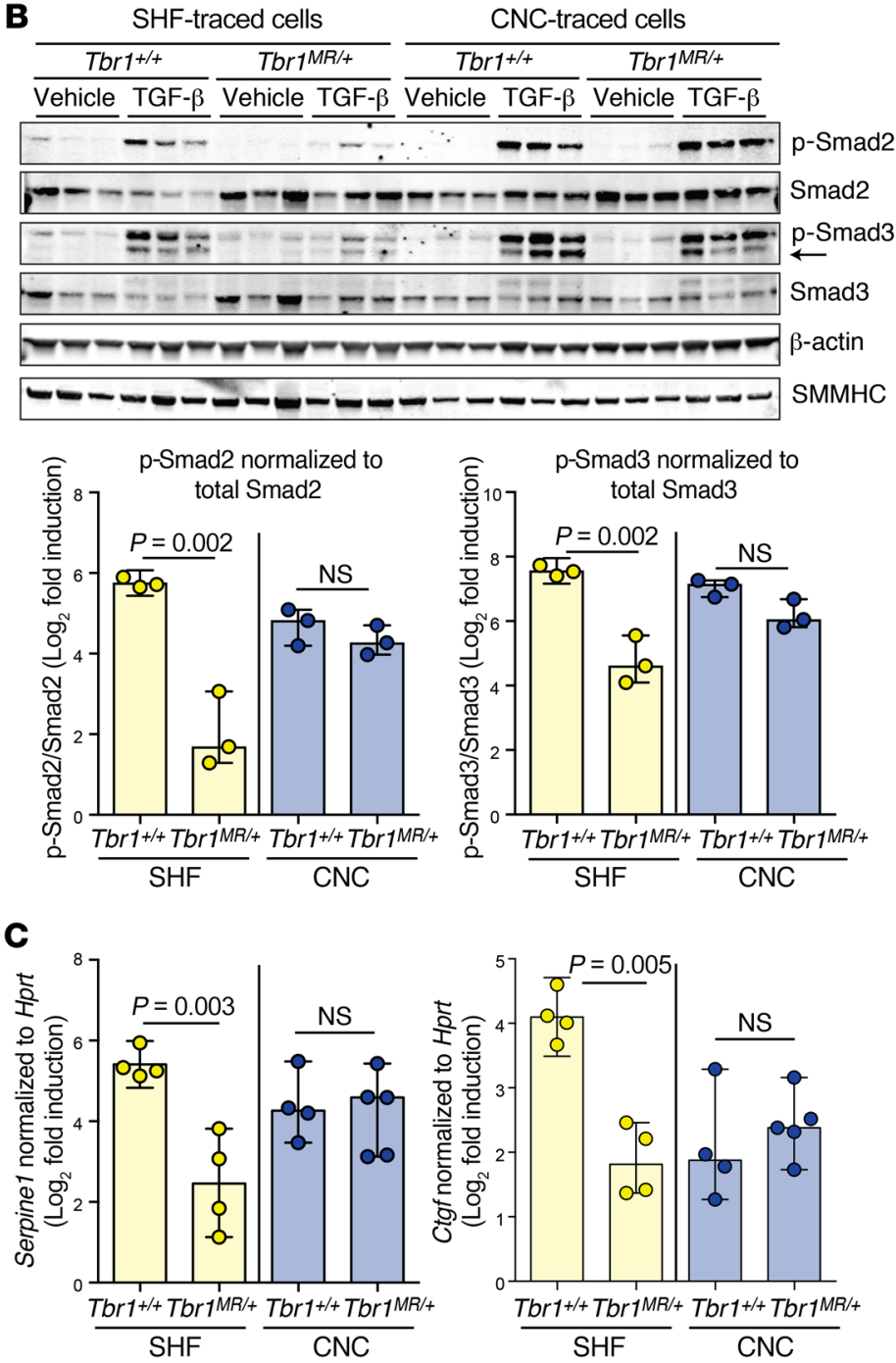

\begin{abstract}
Figure 4. Defective induction of Smad-dependent pathways in SHF-, but not in CNC-derived, primary VSMCs generated from Tbr $^{\text {MR/+ }}$ mice. (A) Representative flow cytometry histogram plots and quantification of $\mathrm{p}-\mathrm{Smad} 2 / 3$ induction over baseline in serum-starved SHF- and CNC-derived VSMCs from mice of the indicated genotypes after exposure to $1 \mathrm{ng} / \mathrm{ml}$ or $10 \mathrm{ng} / \mathrm{ml}$ TCF- $\beta 1$ for 1 hour. Levels of $p-S m a d 2 / 3$ were assessed by phospho-flow cytometry using an antibody specific for $\mathrm{p}-\mathrm{Smad} 2 / 3$ (SHF samples: control $n=5$, mutant $n=4$; CNC samples, control $n=5$, mutant $n=5$ ). $P$ values shown refer to Kruskal-Wallis test with FDR-based multiple comparison correction. (B) Immunoblot of cell lysates from serum-starved SHF and CNC-derived VSMCs stimulated with $1 \mathrm{ng} / \mathrm{ml}$ TCF- $\beta 1$ for 1 hour. Levels of $p-S m a d 2$ and p-Smad3 were assessed with antibodies detecting $\mathrm{p}-\mathrm{Smad} 2$ or $\mathrm{p}-\mathrm{Smad2} / 3$; arrow identifies the band quantified for $\mathrm{p}-\mathrm{Smad} 3$. Quantification of $\mathrm{p}-\mathrm{Smad} 2$ and $\mathrm{p}-\mathrm{Smad} 3$ induction relative to baseline is shown below $(n=3)$. $P$ values shown refer to Kruskal-Wallis test with FDR-based multiple comparison correction. (C) Quantification of normalized Ctgf and Serpine1 induction relative to baseline upon stimulation of serum-starved SHF- and CNC-derived VSMCs from mice of the indicated genotypes with TGF- $\beta 1$ ( $10 \mathrm{ng} / \mathrm{ml}$ ) for 3 hours (SHF samples: control $n=4$, mutant $n=4$; CNC samples, control $n=4$, mutant $n=5$ ). $P$ values shown refer to Kruskal-Wallis test with FDR-based multiple comparison correction. Numerical data are presented as scatter dot-plots with boxes, with the box denoting the mean; error bars identify the $95 \%$ confidence interval. NS, not significant.
\end{abstract}

cell types analyzed revealed heterogeneity in the signaling consequences of this mutation, with $\mathrm{Tbr} \mathrm{I}^{\mathrm{MR} /+}$ adventitial fibroblasts and $T b r 1^{M R /+} \mathrm{T}$ lymphocytes displaying, respectively, normal and attenuated responses relative to their control counterparts (Supplemental Figure 3).

Defective Smad signaling in SHF-derived VSMCs from $\mathrm{Tbr}^{\mathrm{MR} /+}$ mice associates with upregulation of Agtrla, oversensitization to AngII, and increased expression of TGF- $\beta$ ligands. Our previous work has shown that antagonism of the angiotensin II (AngII) type 1 receptor (AT1R) with losartan improves aortic dilation and architecture in a mouse model of LDS carrying a knockin mutation in Tgfbr2, and that this protective effect is associated with reduction of $\mathrm{p}-\mathrm{Smad} 2$ levels in the aortic root (19). Similar results were obtained in the $\mathrm{Tbr}^{\mathrm{MR} /+}$ LDS mouse model, with losartan treatment resulting in reduced aortic root growth and improved aortic wall architecture, with no significant sex-specific differences observed within 


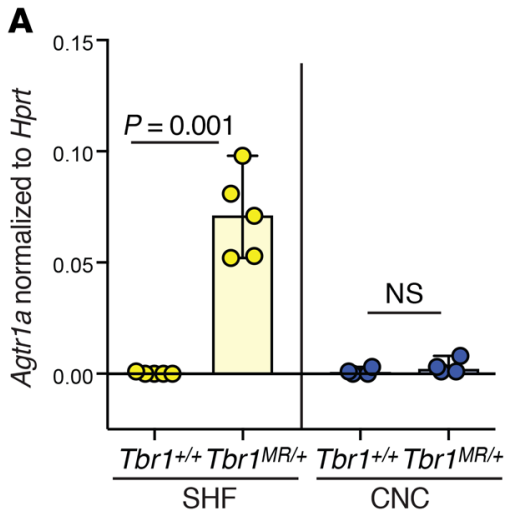

C
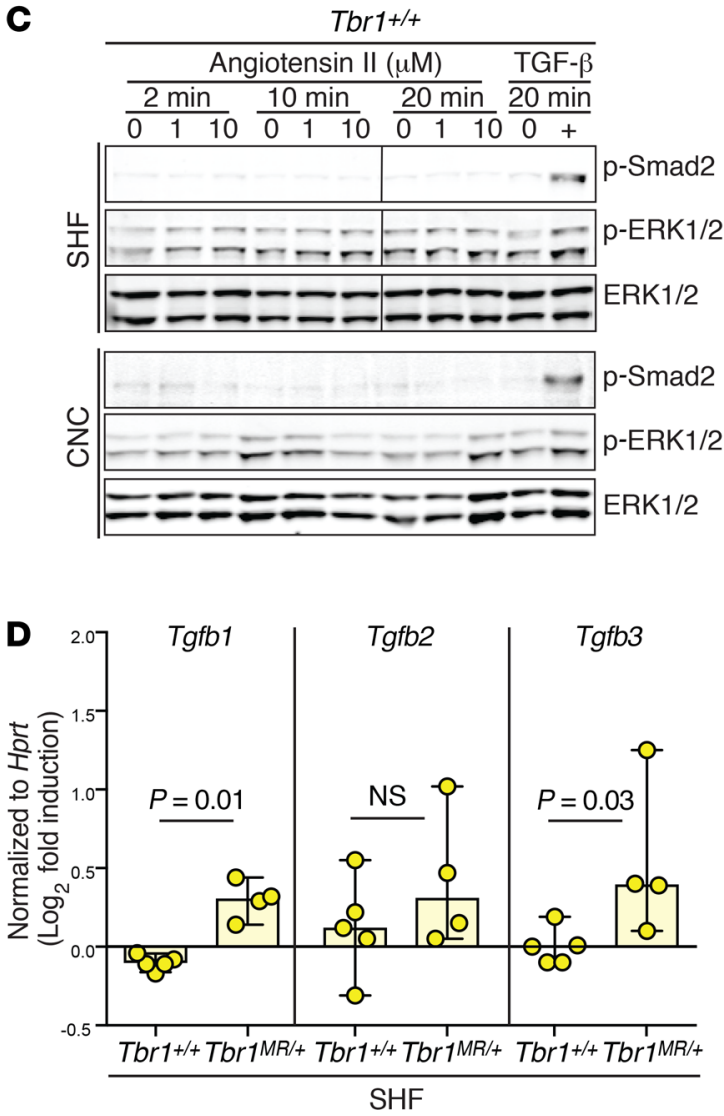
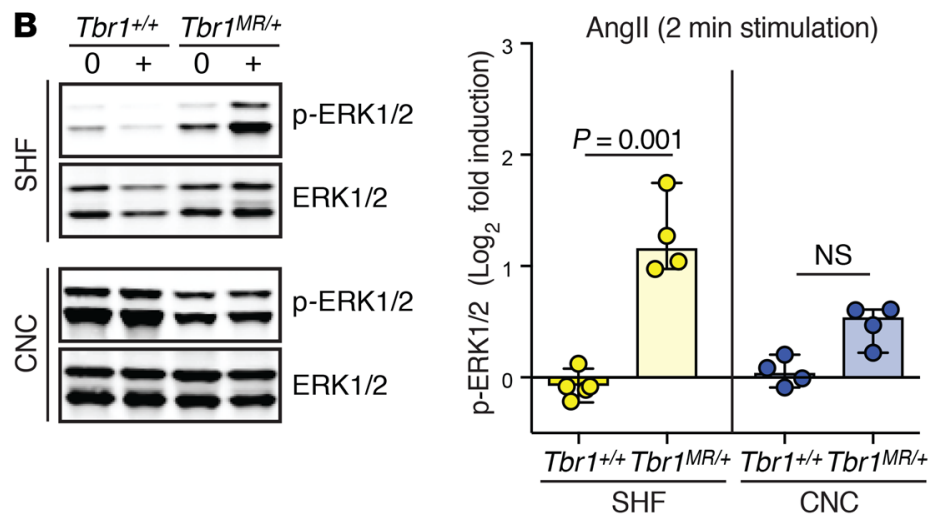

$\operatorname{Tb} 1 \mathrm{MR} /+$
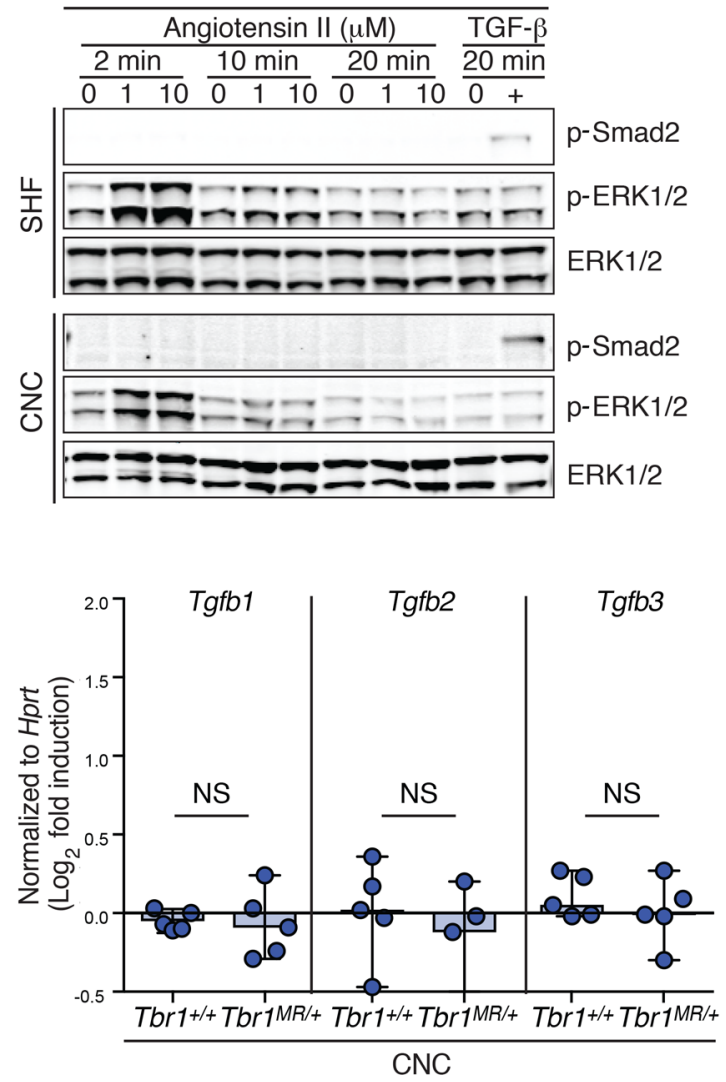

Figure 5. Upregulation of Agtr1a, increased responsiveness to Angll, and increased expression of Tgfb isoforms in SHF-, but not CNC-derived primary VSMCs from Tbr ${ }^{M R /+}$ mice. (A) Normalized Agtr1a mRNA expression in serum-starved SHF- and CNC-derived VSMCs from control (Tbr $\mathrm{T}^{+/+}$) and mutant $\left(\right.$ Tbr $^{\mathrm{MR} /+}$ ) mice cultured in the presence of TGF- $\beta 1(10 \mathrm{ng} / \mathrm{ml})$ (SHF samples: control $n=5$, mutant $n=5$; CNC samples, control $n=4$, mutant $\left.n=4\right)$. $P$ values refer to Kruskal-Wallis test with FDR-based multiple comparison correction. (B) Immunoblot and quantification of p-ERK induction in lysates of SHF- and CNC-derived VSMCs of the indicated genotype cultured as in $\mathbf{A}$ and stimulated with Angll ( $1 \mu \mathrm{M})$ for 2 minutes (SHF samples: control $n=5$, mutant $n=$ 4; CNC samples, control $n=4$, mutant $n=4)$. $P$ values refer to Kruskal-Wallis test with FDR-based multiple comparison correction. (C) Immunoblots of lysates of SHF- and CNC-derived primary VSMCs of the indicated genotype after exposure to Angll (1 or $10 \mu M)$ or TCF- $\beta 1$ (10 ng/ml). No Angll-dependent p-Smad2 induction was detected under any of the conditions. (D) Levels of Tgfb1, Tgfb2, and Tgfb3 induction in serum-starved SHF- and CNC-derived VSMCs of the indicated genotype after exposure to Angll $(10 \mu \mathrm{M})$ for 24 hours (SHF samples: control $n=5$, mutant $n=4$; CNC samples, control $n=5$, mutant $n=5$ ). $P$ values refer to Kruskal-Wallis test with FDR-based multiple comparison correction. Numerical data are presented as scatter dot-plots with boxes, with the box denoting the mean; error bars identify the $95 \%$ confidence interval. NS, not significant.

any group (Supplemental Figure $4, \mathrm{~A}-\mathrm{C}$ ), and in association with reduced levels of p-Smad2/3 (Supplemental Figure 4, D and E). These results prompted us to examine whether AT1R expression or function was increased in VSMCs of $T b r 1^{M R /+}$ mice. In the presence of TGF- $\beta$, Agtrla was overexpressed in $\mathrm{Tbr} 1^{\mathrm{MR} /{ }^{+}} \mathrm{SHF}$-derived
VSMCs relative to their control counterparts; no significant difference was observed between control and mutant CNC-derived VSMCs (Figure 5A and Supplemental Figure 5). Expression of Agtr1b, the other gene coding for AT1R in rodents, was marginal in cultured VSMCs of either lineage or genotype (data not shown). 
A

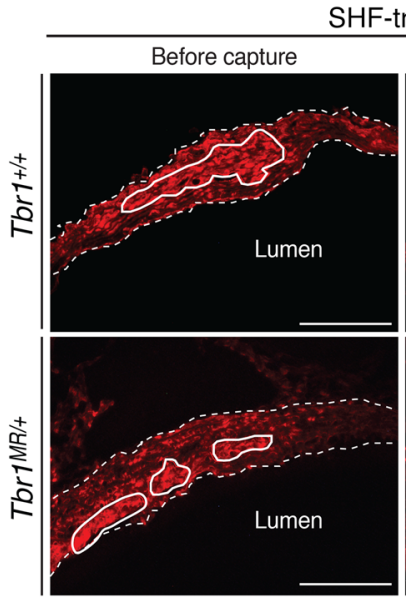

SHF-traced

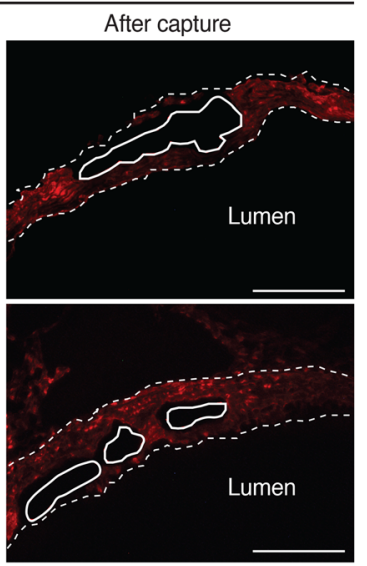

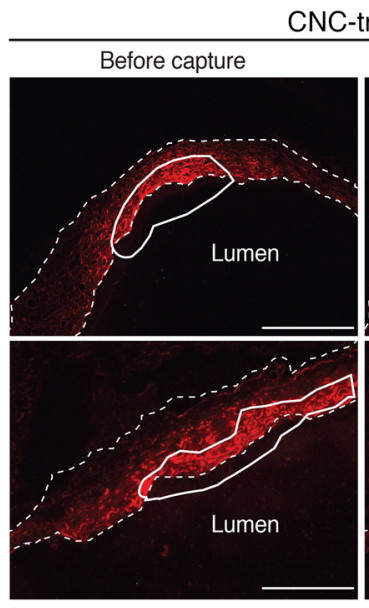

CNC-traced

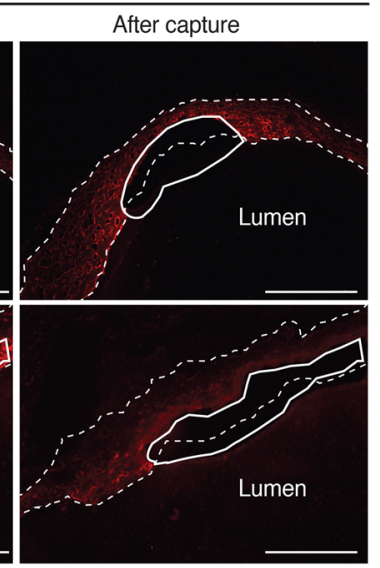

B

SHF-traced tissue
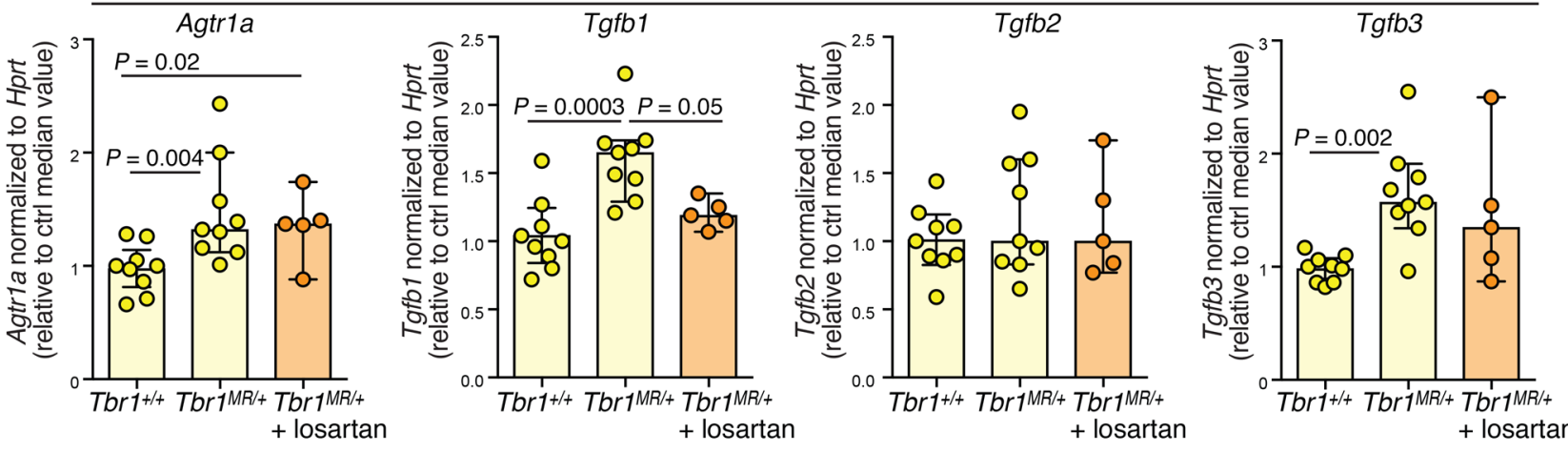

CNC-traced tissue
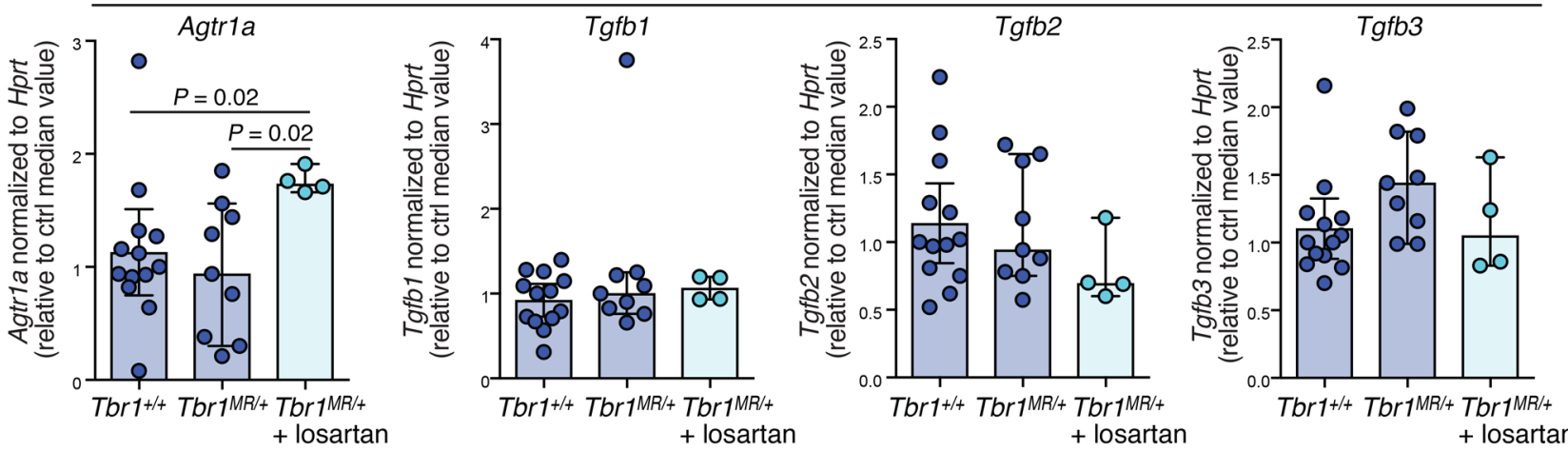

Figure 6. Increased expression of Agtr1a and Tgfb isoforms in SHF-, but not CNC-derived, aortic root tissue from Tbr1 ${ }^{\text {MR/+ }}$ mice. (A) Representative images showing the aortic root of 12-week-old control $\left(\mathrm{Tbr}^{+/+}\right)$and mutant $\left(\mathrm{Tbr}^{\mathrm{MR/+}}\right)$ mice in which SHF- and CNC-derived tissue is marked by expression of TdTomato, taken before and after laser capture. Scale bars: $100 \mu \mathrm{m}$. Experiment was conducted more than 10 times. (B) Expression of the indicated transcripts in SHF- and CNC-derived aortic root tissue obtained by laser-capture microdissection in 12-week-old lineage-traced control ( $\left.\mathrm{Tbr} \mathrm{T}^{+/+}\right)$and mutant $\left(\operatorname{Tbr}^{\mathrm{MR} /+}\right)$ mice, or mutant $\left(\mathrm{Tbr} \mathrm{r}^{\mathrm{MR} /+}\right)$ mice treated with losartan $(100 \mathrm{mg} / \mathrm{kg} / \mathrm{day})$ from 6 to 12 weeks of age (SHF samples: control $n=9$, mutant $n=9$; losar$\tan n=5$; CNC samples, control $n=13$, mutant $n=9$, losartan $n=4$ ). $P$ values refer to Kruskal-Wallis test with FDR-based multiple comparison correction. Numerical data are presented as scatter dot-plots with boxes, with the box denoting the mean; error bars identify the $95 \%$ confidence interval.

Increased expression of Agtrla in Tbr1 ${ }^{M R /+}$ SHF-derived VSMCs correlated with increased AngII-dependent induction of p-ERK, a known downstream mediator of AT1R signaling (39), while no significant difference was observed between CNC-derived VSMCs from control and mutant animals (Figure 5B). Exposure to AngII at doses leading to robust p-ERK induction did not result in induction of p-Smad2 in VSMCs of either lineage or genotype (Figure 5C). In light of increased expression of $T g f b 1$ and $T g f b 3$ in the aortic root of $\mathrm{Tbrr}^{\mathrm{MR} /+}$ mice (Figure 2, A and B), and reports indicating that AngII can induce expression of TGF- $\beta$ in VSMCs (40), we tested whether exposure to AngII increased expression of transcripts coding for TGF- $\beta$ ligands in lineage-traced VSMCs. Stimulation with AngII for 24 hours resulted in a modest but significant upregulation of $T g f b 1$ and $T g f b 3$ mRNA in SHF-derived $\mathrm{Tbr}^{\mathrm{MR} /+}$ VSMCs relative to controls; no significant differences were observed between control and mutant CNC-derived cells 
A

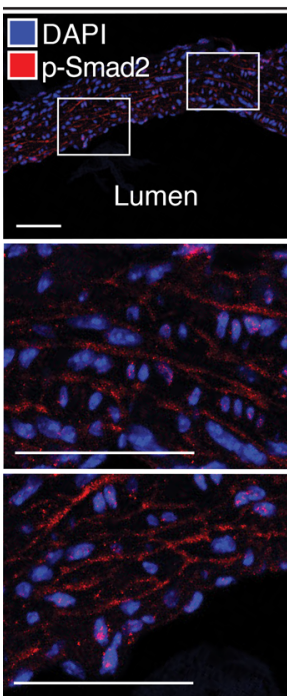

B

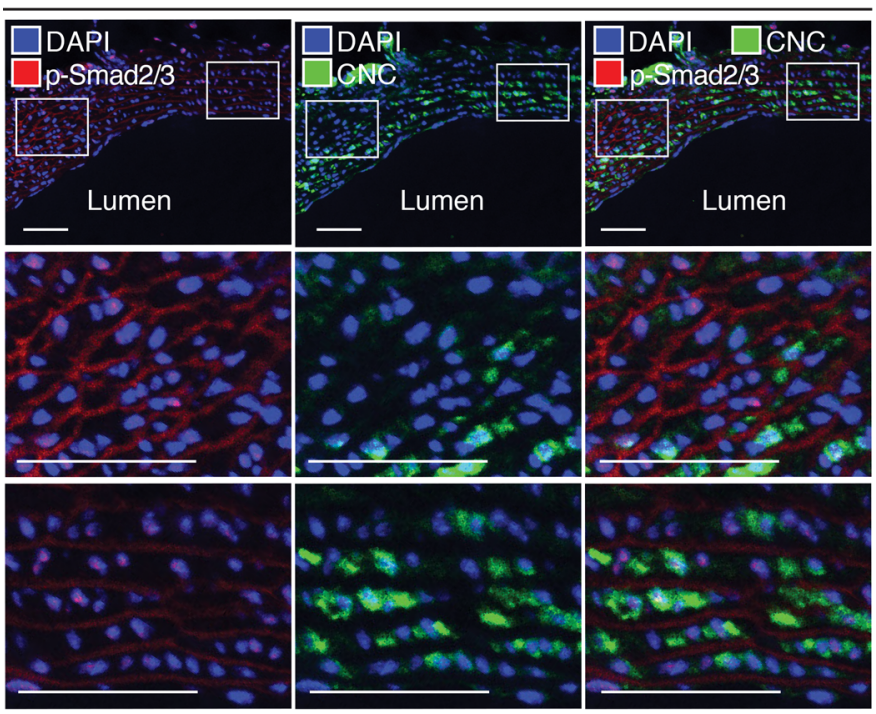

Tbr1+1+

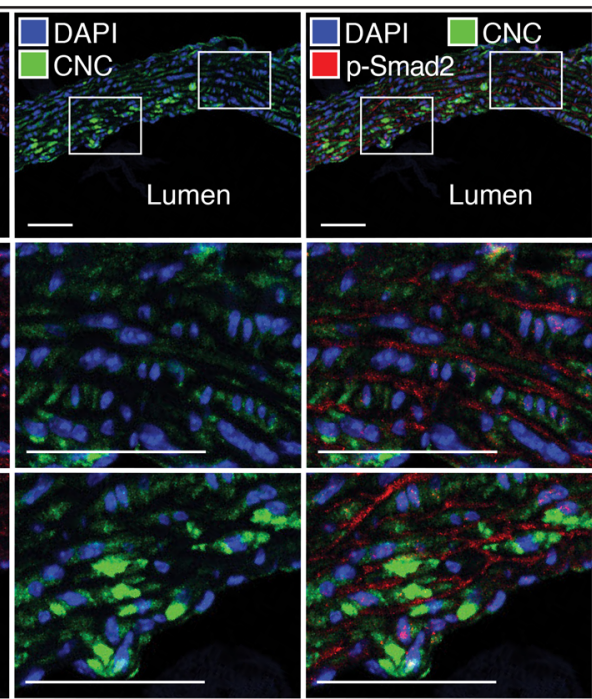

Tbr1+t+

Figure 7. Smad2/3 phosphorylation is enriched in CNC-derived tissue in the aortic root media of $\mathbf{T b r} \mathbf{1}^{\mathrm{MR} /+}$ mice. Representative immunofluorescence

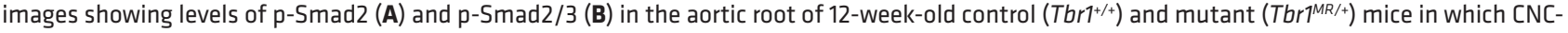
derived tissue is marked by expression of YFP; areas of high and low YFP expression are identified by insets, and shown at higher magnification below each panel. Scale bars: $50 \mu \mathrm{m}$. Experiment was conducted at least 3 times. Image enhancement for visual display was applied uniformly to all panels.

(Figure 5D); minimal induction was observed in either genotype or lineage at an earlier time point (Supplemental Figure 6). In order to validate and extend our in vitro observations, we used laser capture microdissection (LCM) of TdTomato-traced aortic roots (Figure 6A) to obtain SHF- and CNC-enriched tissue from the aortic root of $\mathrm{TbrI}^{1^{+/+}}$and $\mathrm{Tbr} \mathrm{I}^{\mathrm{MR} /+}$ mice at 12 weeks of age, and from $T b r 1^{M R /+}$ mice that had been treated with losartan from 6 to 12 weeks of age, and examined expression of selected transcripts by quantitative PCR (qPCR). While samples from either lineage or genotype expressed similar amounts of TdTomato and Myh11 (Supplemental Figure 7), SHF-derived tissue from the aortic root of $T b r 1^{M R /+}$ mice uniquely showed enhanced expression of Agtrla, $T g f b 1$, and $T g f b 3$, with losartan treatment resulting in normalized expression of $T g f b 1$ in $T b r 1^{M R /+}$ mice (Figure 6B). Expression of
TbrtMR/+

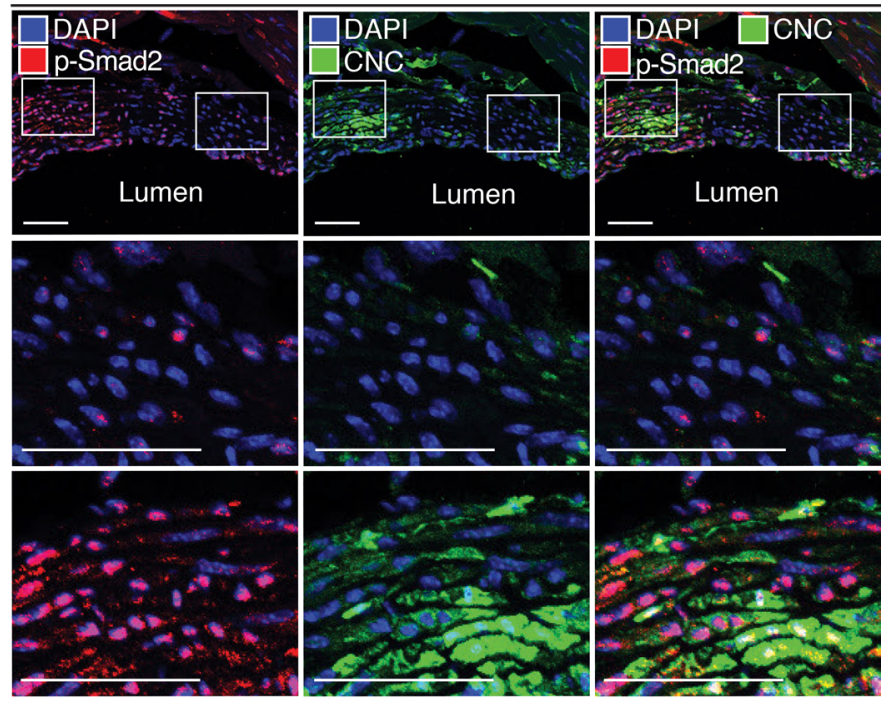

Thr1MR/+

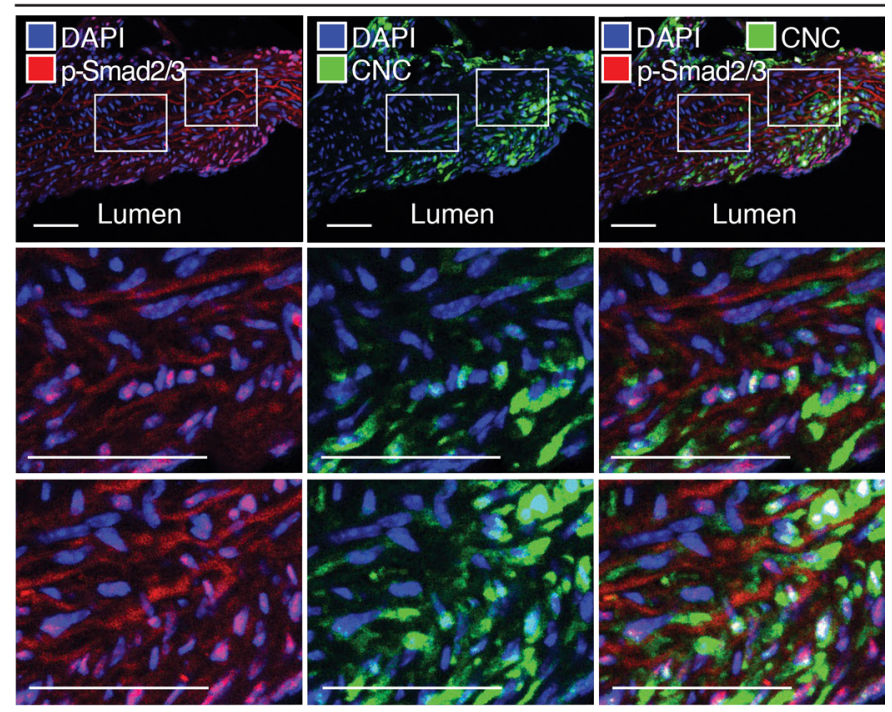

$I N H B A$, the transcript encoding activin A (also known as inhibin, subunit $\beta_{A}$ ), a member of the TGF- $\beta$ family that is also known to induce $\mathrm{p}-\mathrm{Smad} 2 / 3(41,42)$, was not different among groups (Supplemental Figure 7). Consistent with previous reports suggesting that SMAD2 is transcriptionally upregulated in the context of thoracic aortic aneurysm (43), we also observed increased Smad2 mRNA in Tbr1 ${ }^{\text {MR/+ }}$ SHF-, but not CNC-derived aortic tissue; this increase was not reduced by losartan (Supplemental Figure 7).

Smad2/3 phosphorylation is enriched in CNC-derived tissue in the aortic root media of $\mathrm{Tbr}^{\mathrm{MR} /{ }_{+}}$mice, and suppression of Smad 2 signaling in CNC-derived but not SHF-derived cells reduces aortic root pathology in Tbr $^{\text {MR/+ }}$ mice. We reasoned that the observed increase in TGF- $\beta$ ligand production by mutant SHF-derived VSMCs could result in increased $\mathrm{p}-\mathrm{Smad} 2 / 3$ activation by their neighboring signal- 

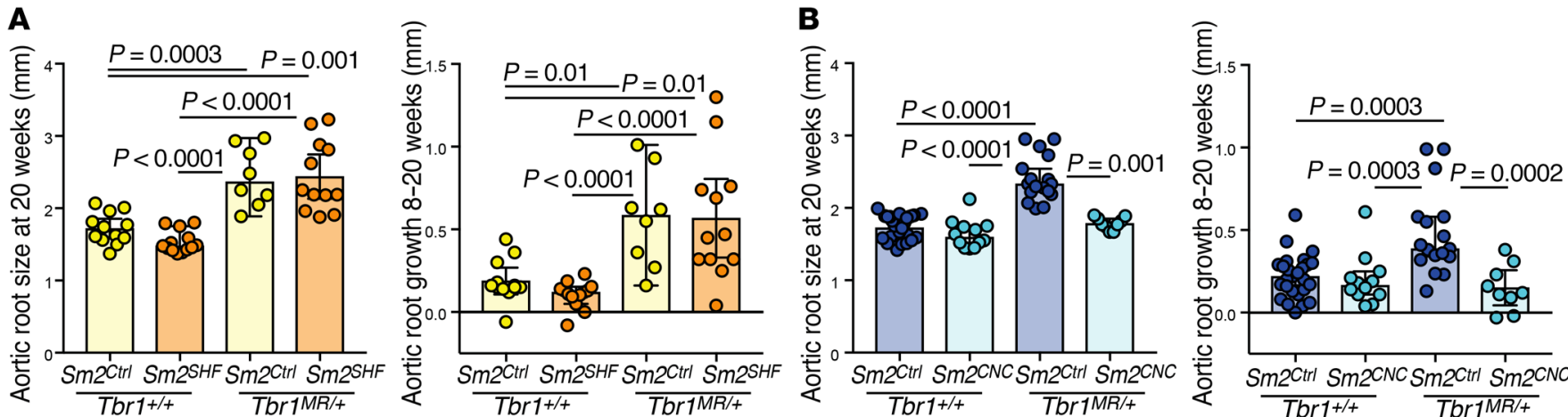

C
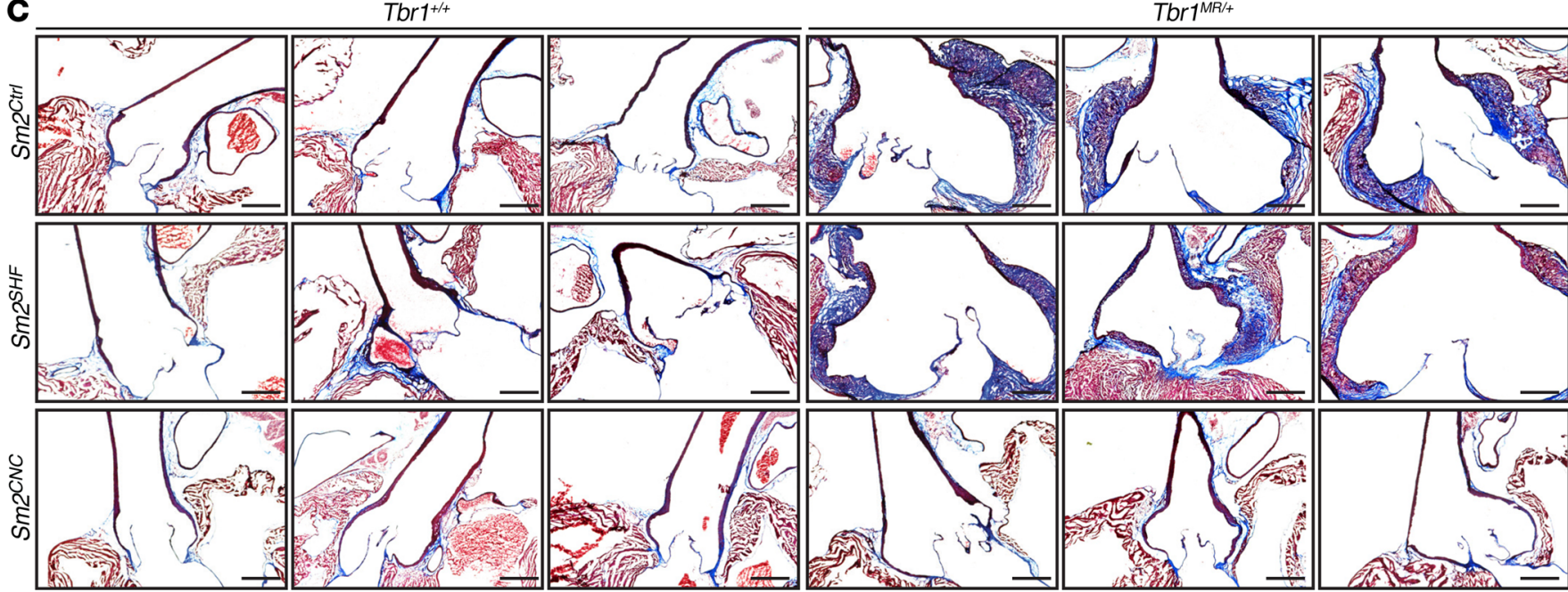

D

Tbr1+/+
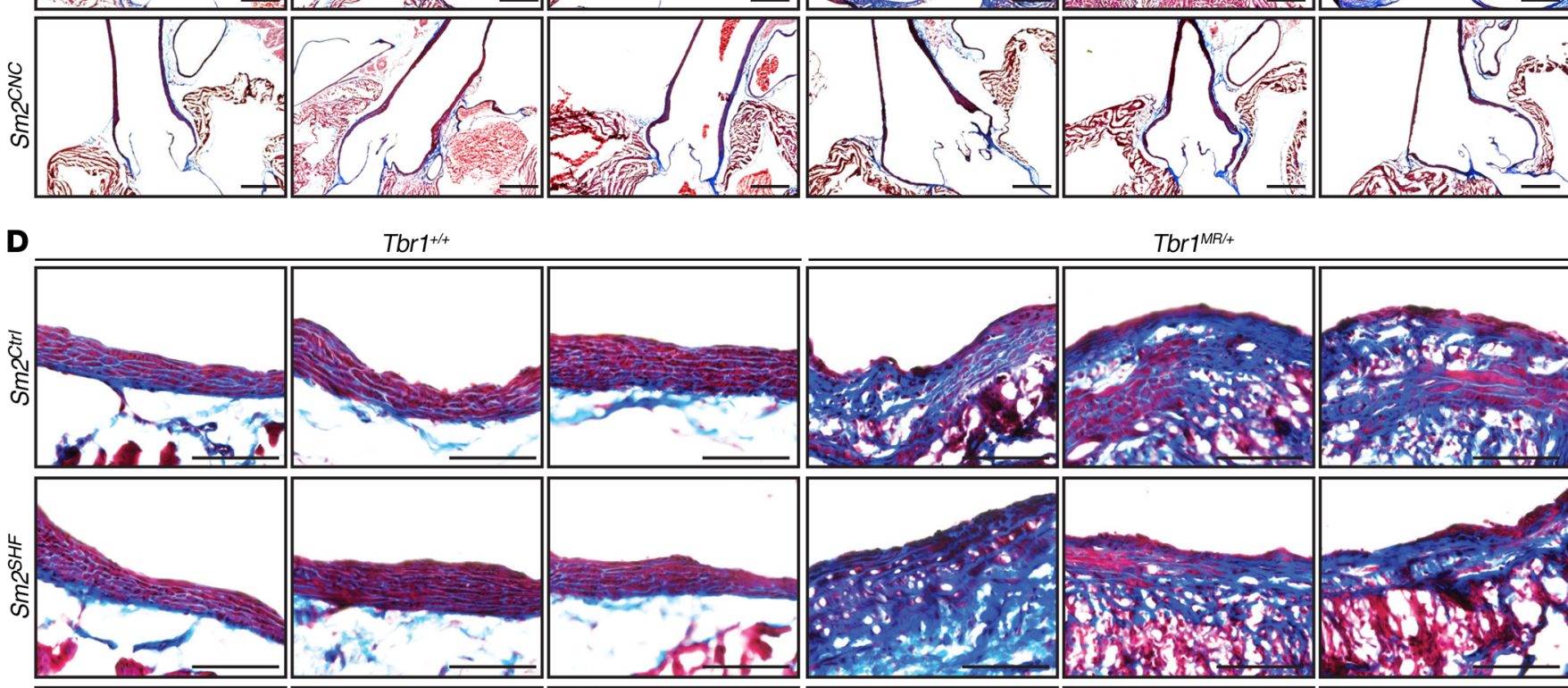

Tbr1 $1^{\text {MR/ }}$
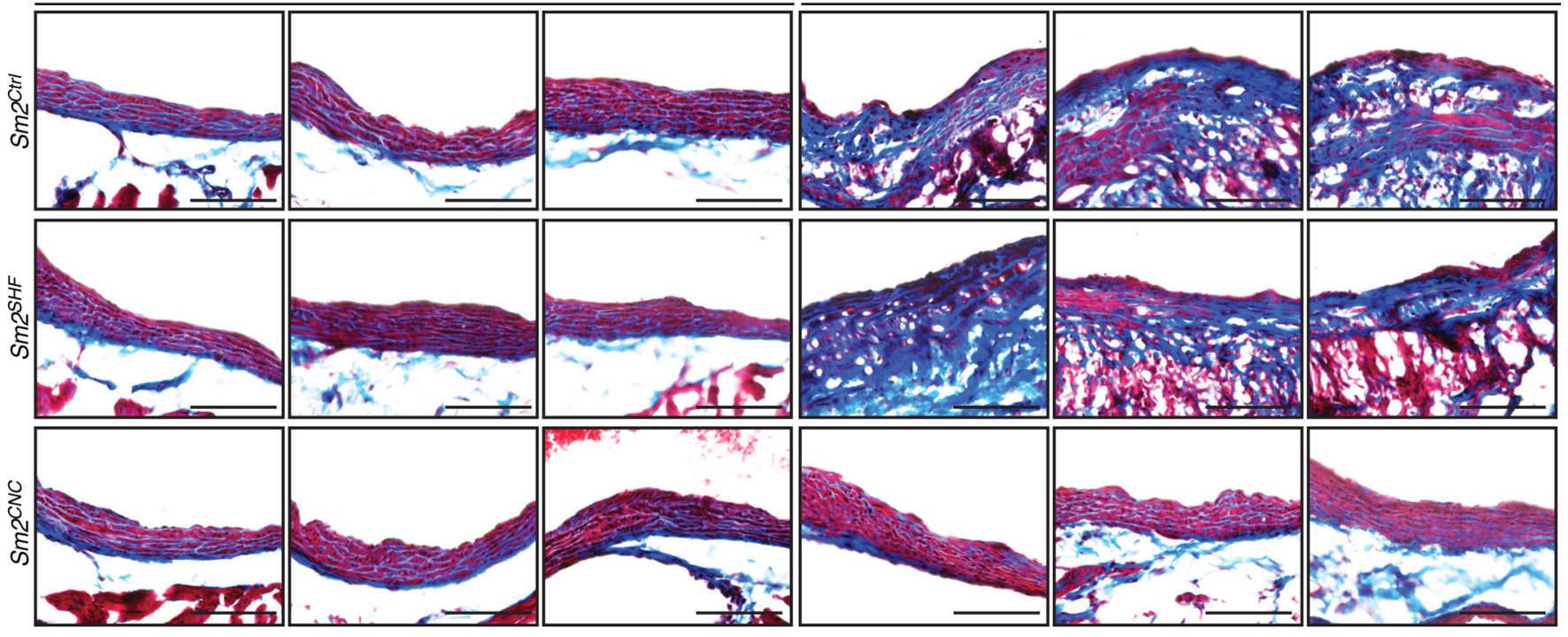

Figure 8. Smad2 deletion in CNC- but not SHF-derived cells ameliorates aortic pathology in Tbr1 ${ }^{M R /+}$ mice. Absolute size and aortic root growth

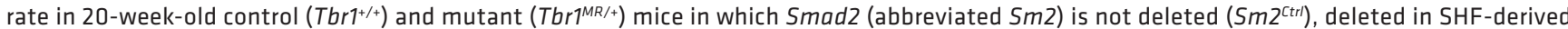
cells $\left(S m 2^{\text {SHF }}\right)(\mathbf{A})$ or deleted in CNC-derived cells $\left(S m 2^{C N C}\right)$ (B) (for all groups $n \geq 8$ ). P values refer to Kruskal-Wallis test with FDR-based multiple comparison correction. (C) Representative images of Masson's trichrome staining of the aortic root of mice of the indicated genotype at 20 weeks of age. Scale bars: $500 \mu \mathrm{m}$. Experiment was conducted at least 3 times. (D) Representative images of Masson's trichrome staining of the aortic root of mice of the indicated genotype at 20 weeks of age. Scale bars: $100 \mu \mathrm{m}$. Image enhancement for visual display was applied uniformly to all panels. Experiment was conducted at least 3 times. Numerical data are presented as scatter dot-plots with boxes, with the box denoting the mean; error bars identify the $95 \%$ confidence interval. 
A
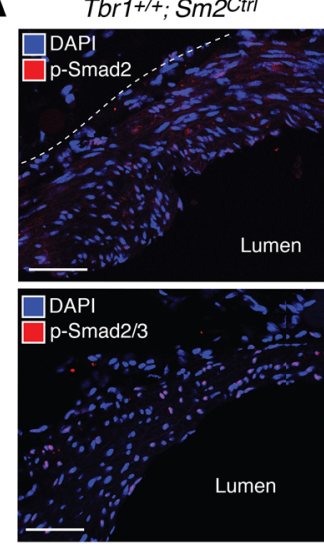

B
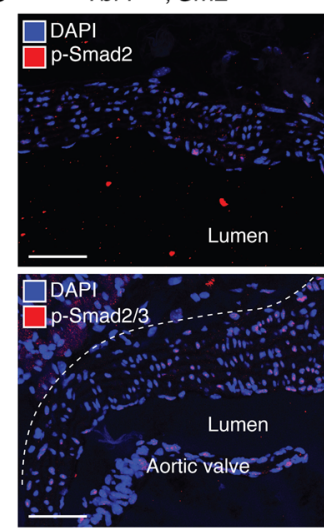

Tbr1MR/+; Sm2Ctrl
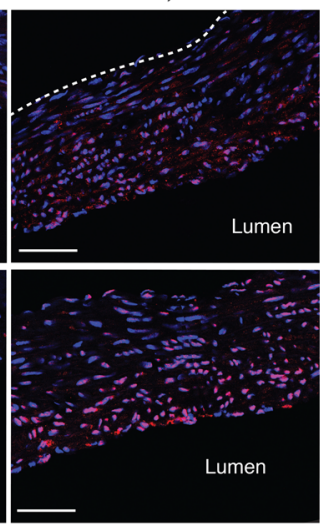

Tbr1MR/+; Sm2Ctrl
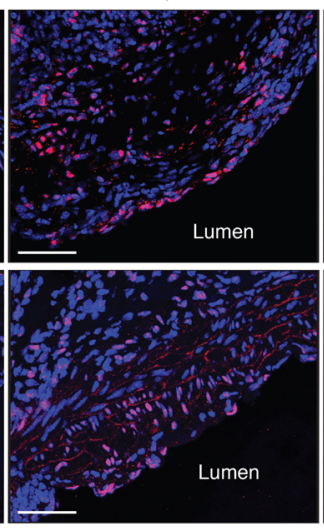

Tbr1MR/+; Sm2SHF
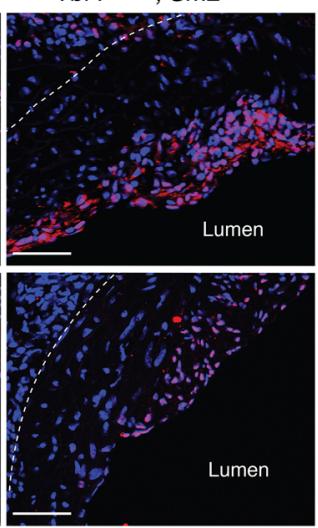

TbriMR/+; Sm2CNC
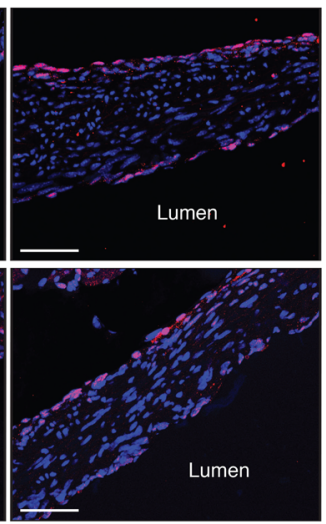

Figure 9. CNC-specific Smad2 deletion associates with decreased Smad2/3 phosphorylation in the aortic root of Tbr $^{\text {MR/++}}$ mice. (A) Representative immunofluorescence (IF) images of the aortic root of 20-week-old control mice $\left(\mathrm{Tbrr}^{+/+}\right.$; $\left.\mathrm{Sm} 2^{\mathrm{Ctr}}\right)$, mutant mice in which $\mathrm{Smad} 2$ is not deleted $\left(\mathrm{Tbr} 7^{\mathrm{MR} / \mathrm{H}}\right.$; $\left.\mathrm{Sm} 2^{(\mathrm{tr})}\right)$, and mutant mice in which Smad 2 is deleted in SHFderived cells ( $\left.\mathrm{Tbr}{ }^{\mathrm{MR} /+} ; \mathrm{Sm} 2^{\mathrm{SHF}}\right)$ stained with an antibody that recognizes $\mathrm{p}-\mathrm{Smad} 2$ or $\mathrm{p}-\mathrm{Smad2} / 3$. Dotted lines mark the outer boundary of the vessel wall. Experiment was conducted at least 3 times. Image enhancement for visual display was applied uniformly to all panels. (B) Representative IF images of the aortic root of 20-week-old control mice $\left(\mathrm{Tbrr}^{\mathrm{T}^{++}} ; \mathrm{Sm} 2^{\mathrm{Ctr}}\right)$, mutant mice $\left(\operatorname{Tbr}^{\mathrm{MR} /+} ; S \mathrm{~m} 2^{\mathrm{Ctr}}\right)$, and mutant mice in which Smad2 is deleted in CNC-derived cells ( $\mathrm{Tbr}^{\mathrm{MR} /+} ; \mathrm{Sm} 2^{\mathrm{CNC}}$ ) stained with an antibody that recognizes $p-S m a d 2$ or $p-S m a d 2 / 3$. Scale bars: $50 \mu \mathrm{m}$. Experiment was conducted at least 3 times. Image enhancement for visual display was applied uniformly to all panels. ing-competent CNC counterparts in the aortic media. In keeping with this hypothesis, we found substantial colocalization between the $\mathrm{CNC}$ lineage and the enhanced $\mathrm{p}-\mathrm{Smad} 2 / 3$ signal in the aortic root media of 12-week-old Tbr $1^{\text {MR/+ }}$ mice (Figure 7 and Supplemental Figure 8). There was no detectable p-Smad 2 in the very distal ascending aorta of LDS mice, where there is overt predominance of CNC-derived VSMCs (Supplemental Figure 8). The medial cells that trace positive for the CNC lineage also expressed SMMHC, attesting to their VSMC identity (Supplemental Figure 9).

In order to examine whether Smad2 signaling in CNC-derived VSMCs is a critical determinant of disease progression, we set out to test the effect of lineage-specific deletion of Smad2 on aortic disease in the LDS mouse model. A previously characterized conditional Smad2 allele (Smad2 $2^{\text {lox/lox}}$ ) (44) was introduced in $\mathrm{Tbr}^{\mathrm{MR} /+}$ mice, and the same transgenic Cre lines used for recombination of conditional fluorescent reporter alleles (Figure 3) were used for lineage-specific deletion. Ultrasound measurements did not find any significant differences in aortic root size or growth between male and females mice within any experimental groups (Supplemental Figure 10), and thus these data are presented in aggregate (Figure 8). Despite previous reports on the deleterious effects of CNC-specific Smad2 deletion in adult carotid arteries (45), Smad2 deletion in either lineage did not alter aortic root growth, size, or architecture in control mice (Figure 8, A-D). In contrast, deletion of Smad 2 in CNC-derived cells, but not in SHF-derived cells, normalized aortic root size and growth rate (Figure $8, \mathrm{~A}$ and $\mathrm{B}$ ), and aortic wall architecture (Figure 8, C and D) in Tbr $1^{\mathrm{MR} /+}$ mice. Deletion of Smad2 in SHF- or CNC-derived cells did not have any sig- nificant effect on the diameter of the more distal ascending aorta (Supplemental Figure 10). In keeping with previous observations in this model of LDS, which shows high survival (85\%-90\%) at 140 days (19), no significant differences in viability were observed between genotypes by the endpoint of 20 weeks (Supplemental Figure 10). Deletion of Smad2 in SHF-derived cells did not result in worsening or amelioration of disease in $\mathrm{Tbr}^{\mathrm{MR} /{ }^{+}}$mice; in these mice, $\mathrm{p}-\mathrm{Smad} 2 / 3$ staining was most prevalent on the luminal side of the aortic media, a region enriched with CNC-derived cells (21, 46) (Figure 9A). In contrast, amelioration of disease by CNC-specific deletion of $S m a d 2$ was associated with an overall reduction in p-Smad2/3 (Figure 9B). Although it is possible that Smad2 deletion in other CNC-derived cell-types might contribute to amelioration of disease, these results show that a manipulation intended and observed to decrease Smad signaling in CNC-derived VSMCs leads to amelioration of aortic pathology in a mouse model of LDS.

\section{Discussion}

The study of monogenic syndromic presentations of thoracic aortic aneurysm has implicated perturbation of TGF- $\beta$ signaling in disease pathogenesis (2). Primary mutations have been identified in genes encoding factors along the entire TGF- $\beta$ signaling cascade, including extracellular regulators of TGF- $\beta$ bioavailability (fibrillin-1 or biglycan), TGF- $\beta$ ligands (TGF- $\beta 2$ or TGF- $\beta 3$ ), receptor subunits (T $\beta$ RI or T $\beta R I I)$, as well as positive (SMAD2, SMAD3) and negative (SKI) signaling effectors (12-18, 47-51). Ambiguity about the precise role of TGF- $\beta$ in vessel wall homeostasis has arisen because of apparently contradictory observations and 


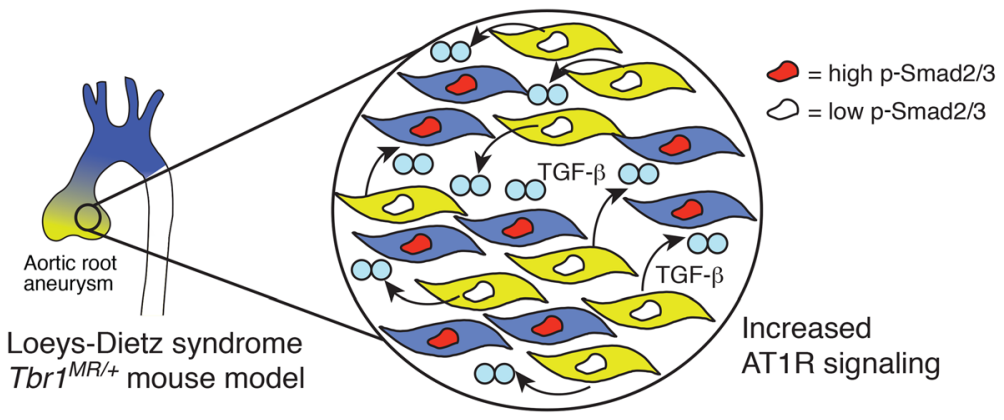

SHF-derived VSMCs

CNC-derived VSMCs
Figure 10. Model for aortic pathogenesis associated with LoeysDietz syndrome. In the $\mathrm{Tbr} \mathrm{r}^{\mathrm{MR} /+} \mathrm{LDS}$ mouse model, a heterozygous kinase-inactivating missense mutation in Tgfbr1 (Tgfbr $7^{\mathrm{M} 318 R /+}$ ) associates with defective TCF- $\beta$ signaling in SHF-derived cells, while CNC-derived cells retain normal signaling capacity. Defective Smad2/3 signaling in SHF-derived cells associates with upregulation of Agtr1a gene expression, and AT1R-dependent overexpression of TGF- $\beta$ ligands. In the presence of increased levels of TCF- $\beta$, CNC-derived cells show increase levels of $p-5 \operatorname{mad} 2 / 3$, which contributes to pathogenesis. Treatment with the AT1R inhibitor losartan and CNC-specific Smad2 ablation ameliorates disease. Additional cell types, such as adventitial fibroblasts, endothelial cells, and recruited immune cells might also contribute to increased TCF- $\beta$ expression and/or activation at sites of disease. inferences regarding loss or gain of TGF- $\beta$ activity in the pathogenesis and treatment of disease (22-24). While protective therapeutic trials in preclinical models associate with attenuation of biochemical and gene expression signatures indicative of TGF- $\beta$ signaling $(19,48,52-56)$, ambiguity remains as to the relative contribution of TGF- $\beta$ inhibition to disease amelioration, and the role of TGF- $\beta$ signaling as a primary driver or a nonspecific late-stage consequence of disease $(21,24,46,56,57)$. Ongoing controversy has also been fueled by the observation that genetic abrogation of TGF- $\beta$ signaling in VSMCs can result in severe and widespread aortopathy, or exacerbation of vessel wall disruption caused by other insults such as AngII infusion or genetic predisposition for aneurysm (58-65). In these studies, however, the phenotype is often hyperacute, evolving from predisposition to death in a matter of days, overtly inflammatory, and of debatable relevance to genetic presentations of thoracic aortic aneurysm that manifest over months in mouse models, and decades in people.

In this study, we present data in support of a model in which paracrine interactions between SHF- and CNC-derived VSMCs are initiated by defective Smad2/3 signaling in $\mathrm{Tbr}^{\mathrm{MR} /{ }^{+}} \mathrm{SHF}$-derived cells, and through excessive AT1R-dependent increase in TGF- $\beta$ expression, culminate in pathogenic $\mathrm{p}-\mathrm{Smad} 2 / 3$ signaling in neighboring $\mathrm{Tbr}^{\mathrm{MR} /{ }^{+}} \mathrm{CNC}$-derived cells in the aortic root (Figure 10). This model integrates the apparently discordant foundational observations supporting both loss and gain of $\mathrm{p}-\mathrm{Smad} 2 / 3$ signaling as drivers of disease, and the localized vulnerability to dilation and associated signaling abnormalities in the aortic root of LDS mice and patients $(3,19,66)$. We speculate that the peculiar predisposition to dilation in the aortic root, and not in the ascending aorta, where SHF- and CNC-derived VSMCs are also found, depends on at least two factors. First, the unique hemodynamic environment of this vascular segment might contribute to diverse factors that promote aneurysm progression, including activation of latent TGF- $\beta$ and ligand-independent AT1R triggering by mechanical stretch (57, 67-72). Second, while SHF- and CNC-derived VSMCs tend to mingle in the aortic root - a circumstance that logically would promote paracrine interactions - they occupy more spatially distinct domains in the more distal ascending aorta (36) (Figure 3C).

Our in vitro studies document the particular vulnerability of SHF-derived VSMCs to the consequence of a heterozygous lossof-function mutation in a positive effector of TGF- $\beta$ signaling (Figure 4). Decreased $\mathrm{p}-\mathrm{Smad} 2 / 3$ signaling in $\mathrm{Tbr} \mathrm{I}^{\mathrm{MR} /{ }^{+}} \mathrm{SHF}$-derived VSMCs associates with increased levels of Agtrla mRNA and
AngII-mediated induction of TGF- $\beta$ ligand expression, which, in vivo, can be attenuated by treatment with the AT1R antagonist losartan (Figures 5 and 6). Notably, localized upregulation of $T g f b 1$ expression has been observed at sites of dilation in other forms of LDS, such as those caused by haploinsufficiency in TGF- $\beta$ ligands $(14,16)$ and intracellular signaling mediators $(13)$, suggesting that this might be a common feature of aneurysm syndromes associated with partial inhibition of TGF- $\beta$ signaling. Although the change in $T g f b 1$ expression is modest, a disease model in which a small but sustained change in local TGF- $\beta$ ligand concentration contributes to pathogenesis is consistent with the observation that, in both patients and mouse models, loss of vessel wall homeostasis is a slow evolving process, which is quite different from the hyperacute events observed after overt genetic or pharmacological provocations (59-62, 64, 65). Other cell types, including adventitial fibroblasts and immune cells recruited to the site of disease might also contribute to elevated levels of TGF- $\beta$ ligand expression and/or activation at sites of disease $(65,72,73)$.

Our prior manuscript showed no therapeutic (or detrimental) effect of treatment with TGF- $\beta$-neutralizing antibody, and no influence of this intervention on $\mathrm{p}-\mathrm{Smad} 2 / 3$ in the aortic media of LDS mice (19). In Marfan syndrome (MFS) models, this intervention can have therapeutic effects in association with attenuation of p-Smad2/3 $(48,74,75)$, but this is highly context specific, with variation from beneficial to neutral to detrimental based on background or developmental stage (56). Although it is possible that other signaling cascades are driving enhancement of $\mathrm{p}-\mathrm{Smad} 2 / 3$ in $\mathrm{Tbr}^{\mathrm{MR} /{ }^{+}} \mathrm{CNC}$-derived VSMCs, we provide evidence against a direct role for either activin A (Supplemental Figure 7) or AngII (Figure 5C) in the activation of $\mathrm{p}-\mathrm{Smad} 2 / 3$ in the aortic root. Epigenetic regulation resulting in higher Smad2 mRNA expression has also been proposed as a TGF- $\beta$-independent mechanism to explain increased levels of p-Smad2 (43). However, in our analysis, only $T b r 1^{M R /+}$ SHF-enriched tissue showed elevated levels of Smad 2 mRNA, while Smad2 levels in $\mathrm{Tbr}^{\mathrm{MR} /{ }_{+}} \mathrm{CNC}$-enriched tissue, where the majority of $\mathrm{p}-\mathrm{Smad} 2 / 3$ signal localized (Figure 7 ), were not increased relative to controls; furthermore, losartan treatment lowered levels of p-Smad 2 but not Smad 2 mRNA levels (Supplemental Figures 4 and 7). In view of all these considerations, the failure of TGF- $\beta$-neutralizing antibody treatment to suppress $\mathrm{p}$-Smad2/3 and ameliorate disease in LDS mouse models seems more likely to be explained by issues related to bioavailability, as also observed in other TGF- $\beta$-related pathologies (76), rather than 
by TGF- $\beta$-independent $\mathrm{p}-\mathrm{Smad} 2 / 3$ induction. In this light, it is also notable that chronic treatment of mice with TGF- $\beta$-neutralizing antibody - as an isolated provocation - is not sufficient to induce aortic dilation $(19,56,64)$.

The mechanism for the discordant effect of the Tgfbr1 ${ }^{\mathrm{M} 318 R /+}$ mutation on SHF-derived and CNC-derived VSMCs is currently unknown; we hypothesize that the ability of CNC-derived VSMCs to retain normal signaling might relate to differential expression of signaling modulators in these two lineages.

The CNC-specific upregulation of $\mathrm{p}-\mathrm{Smad} 2 / 3$ at early stages of disease might also explain the observation that elevation of $\mathrm{p}-\mathrm{Smad} 2 / 3$ in the aortic root of $T b r 1^{\mathrm{MR} /{ }_{+}}$mice can be observed in situ but not when averaging techniques are used to assay other or broader aortic segments. Xie and colleagues have documented the consequences of CNC-specific Smad2 deletion on aortic arch arteries, and specifically the carotid arteries, with no comment, however, upon the status of CNC-derived structures in the aorta (45). The phenotype they describe, thinner and fewer elastic lamellae, is reminiscent of observations made with elastin haploinsufficiency, which can include vascular stenosis but not aneurysms $(77,78)$. Recent human genetics data suggest that germline haploinsufficiency for SMAD2 can associate with a very mild, late-onset, and poorly penetrant aortic aneurysm phenotype (17, 18). We clearly do not see this predisposition in mice with isolated targeting of either lineage, at least in our background and within the time frame of observation (Figure 8). It is possible that TGF- $\beta$ signaling via Smad3 is sufficient to allow normal VSMC differentiation and tissue homeostasis in some contexts; this is consistent with the observations that Smad3 is the primary Smad that regulates transcription of VSMC differentiation genes $(79,80)$.

Extensions of this work may more broadly inform the basis for focal and regional aneurysm predisposition in LDS and other inherited aortopathies (3). A large amount of data from multiple groups has revealed a signature for high $\mathrm{p}-\mathrm{Smad} 2 / 3$ in the aortic wall of MFS patients and mouse models $(48,74,75,81,82)$. Prior work has suggested that fibrillins can positively regulate TGF- $\beta$ signaling by concentrating this cytokine at sites of intended function, but negatively regulate TGF- $\beta$ activation through sequestration of its latent form $(83,84)$. It remains possible that low concentrations of TGF- $\beta$ in the fibrillin-1-deficient aortic root might mimic the influence of TGF- $\beta$ receptor mutations in the SHF-derived cells, leading to increased TGF- $\beta$ production - and perhaps a greater tendency for activation in the absence of efficient matrix sequestration. Importantly, these potential effects are not mutually exclusive.

A comprehensive understanding of lineage-specific events will require consideration of additional triggers, potentially including dynamic biomechanical factors $(57,71)$ and lineage-specific interactions between VSMCs and other cell types (85). For example, it has been well documented that the more distal ascending aorta and the proximal descending thoracic aorta, both encompassing the domain of CNC-derived cells, show enhanced risk of progressive enlargement and dissection after prophylactic surgery that replaces the normally compliant and elastic aortic root with stiff synthetic material in both MFS and LDS patients $(4,6,86)$; this risk can be modulated with AT1R antagonists (87). The mechanistic basis for this observation is not well understood but plausibly involves an interaction between perturbation of regional hemodynamics and cell type-specific signaling responses. This study highlights the need to consider and define the microenvironments within which genetic alterations exert their phenotypic influence in order to elucidate pathogenic mechanisms and design therapeutic interventions.

\section{Methods}

Mice. Generation of $T b r 1^{M R /+}$ mice, which are maintained on a 129S6/ SvEv background, has been previously described (19). Mice carrying the Wnt1-Cre1 (34) (stock 009107), R26R-YFP (88) (stock 006148), R26R-TdTomato (89) (stock 007905), and conditional allele for Smad2 (44) (stock 022074) were purchased from The Jackson Laboratory. Mice carrying the $\mathrm{Mef} 2 \mathrm{C}^{\mathrm{SHF}}$-Cre (33) allele were a gift of the laboratory of K.R. Chien (Cardiovascular Research Center, Massachusetts General Hospital, Boston, Massachusetts, USA), with permission from the laboratory of B. Black (Cardiovascular Research Institute, UCSF, San Francisco, California, USA). All strains were backcrossed to $129 \mathrm{~S} 6 / \mathrm{SvEv}$ mice for at least 4 generations prior to intercrossing with $\operatorname{Tbr}^{\mathrm{MR} /+}$ mice. Mice carrying the Wnt1-Cre2 (35) (stock 022137, already on a 129S4 background) were purchased from The Jackson Laboratory and crossed to $\mathrm{Tbr} \mathrm{I}^{\mathrm{MR} / \mathrm{+}}$ mice, without any additional backcrossing. For lineage tracing of CNC-derived cells, Wnt1-Cre1 (34) and Wnt1-Cre2 (35) mice were used interchangeably in conjunction with either R26R-YFP or R26R-TdTomato lineage-tracer alleles. Wnt1-Cre2 (35) mice were used for lineage-specific deletion of Smad2 in CNC-derived cells because the Wnt1-Cre1 transgene (34) resulted in seizures when crossed to $\mathrm{Tbr} \mathrm{I}^{\mathrm{MR} /+}$; Smad2 mutant strains. Losartan diet was designed to deliver $3 \mathrm{mg}$ of drug per day (approximately 100 $\mathrm{mg} / \mathrm{kg} /$ day); control mice received a diet of identical formulation that did not contain losartan (Envigo). Within their respective group (as defined by either $T b r 1^{+/+}$or $T b r 1^{M R /+}$ ), we did not observe any phenotypic differences between $\operatorname{Smad2}^{+/+}, \mathrm{Smad2}^{\text {lox } / \text { lox }}$, Smad2 2+/; Wnt1-Cre2, and $\mathrm{Smad2}_{2++}$; Mef2 $\mathrm{C}^{\mathrm{SHF}}$-Cre mice, and these animals are collectively referred to as Smad2 ${ }^{C t r l}\left(S m 2^{C t r l}\right)$. Smad2 $2^{\text {lox/lox}} ;$ Wnt1-Cre2 are referred to as $S m a d 2^{C N C}\left(S m 2^{C N C}\right)$ and $S m a d 2^{l o x} / l o x ; M e f 2 C^{S H F}$-Cre are referred to as $\operatorname{Smad} 2^{S H F}\left(S m 2^{S H F}\right)$. Littermates and age-matched cohort mates were used as controls; no formal randomization method was used; numbers of male and female individuals used in each experimental group are reported in Supplemental Table 1; no explicit power analysis was used, and sample size was estimated based on previous published and unpublished work.

Aortic tissue processing for protein extraction. Dissection of the entire heart and thoracic aorta was performed as previously described (19). Aortic root and ascending aorta were dissected after flushing the left ventricle with approximately $5 \mathrm{ml} \mathrm{PBS} \mathrm{(pH} \mathrm{7.4).} \mathrm{Tissue} \mathrm{was}$ snap-frozen in liquid nitrogen and stored at $-80^{\circ} \mathrm{C}$ until processing. Protein was extracted using an automatic bead homogenizer, and beads/lysis reagents from the Protein Extraction Kit (Full Moon Biosystems). All buffers contained protease and phosphatase inhibitors (MilliporeSigma).

Immunoblots and related antibodies. All immunoblots were performed using standard techniques, secondary antibodies conjugated to IRdye-700 (for mouse antibodies) or IRdye-800 (for rabbit antibodies), LI-COR buffer and LI-COR Odyssey visualization system; stripping, if required, was performed with NewBlot PVDF $5 \times$ Stripping Buffer and verified with LI-COR Odyssey visualization system. 
The following antibodies were used to examine aortic protein lysates: anti-p-Smad2 (clone A5S, MilliporeSigma), anti- $\beta$-actin (Cell Signaling Technology, catalog 3700), anti-TGF- $\beta 1$ (Abcam, ab179695), anti-TGF- $\beta 2$ (Abcam, ab113670), and anti-TGF- $\beta 3$ (Abcam, ab15537). The following antibodies were used to assess signaling responses in cultured cells: anti-p-Smad2 (Cell Signaling Technology, catalog 3101), anti-total Smad2 (Cell Signaling Technology, catalog 3103), anti-p-Smad3 (Abcam Ab52903), anti-total Smad3 (Cell Signaling Technology, catalog 9523), anti-SMMHC (Abcam, ab53219), anti- $\beta$ actin (MilliporeSigma, catalog A5316), anti-p-ERK1/2 (Cell Signaling Technology, catalog 4370), anti-ERK1/2 (Cell Signaling Technology, catalog 9107), anti-p-Akt (Ser473) (Cell Signaling Technology, catalog 4060), and anti-pan-Akt (Cell Signaling Technology, catalog 2920).

Immunofluorescence and histology. Dissection of the entire heart and thoracic aorta en bloc was performed as previously described (19). After flushing with approximately $5 \mathrm{ml}$ of PBS, the heart was flushed with $5 \mathrm{ml}$ of freshly prepared $4 \%$ paraformaldehyde (PFA) (Electron Microscopy Sciences) in PBS, and then fixed in fresh $4 \%$ $\mathrm{PFA}$ at $4^{\circ} \mathrm{C}$ overnight. Tissue was then incubated in antigen retrieval solution (10 mM sodium citrate buffer, $\mathrm{pH} 6.0$ ) at $4^{\circ} \mathrm{C}$ overnight prior to being immersed in boiling antigen retrieval solution for 3 minutes. After this antigen retrieval step, which is critical for successful probing of p-Smad2/3, tissue was immersed in cold 30\% sucrose in PBS and incubated at $4{ }^{\circ} \mathrm{C}$ overnight prior to being embedded and frozen in Tissue-Tek OCT compound. Sections $(10 \mu \mathrm{m})$ were cut in a longitudinal axis view using a cryostat and left to dry for at least 1 day at room temperature prior to incubation with antibody or other staining reagents. For immunofluorescence staining, sections were first permeabilized in PBS containing 0.1\% Triton X-100 and 0.3 M glycine for 20 minutes, then incubated with Fc Receptor Blocker (Innovex) for 20 minutes at room temperature, and then Background Buster (Innovex) for another 20 minutes at room temperature. Primary antibodies were diluted at 1:100 in staining buffer ( $0.1 \%$ Triton X-100 in PBS) and incubated overnight at $4^{\circ} \mathrm{C}$. Three consecutive washes were performed prior to incubation with anti-rabbit secondary antibody conjugated to Alexa Fluor 594 (Invitrogen, R37119) or Alexa Fluor 555 (Invitrogen, A-31572) at 1:200 for 1 hour. If double staining for the YFP antigen was performed, slides were then incubated with anti-YFP antibody for 1 hour at room temperature, washed 3 times, and then incubated with anti-chicken Alexa Fluor 488 conjugate secondary antibody (Invitrogen, A-11039) at 1:200 for 1 hour. Slides were again washed 3 times prior to mounting with VECTASHIELD Hard Set Mounting Media with DAPI (H-1500). The following primary antibodies were used: anti-p-Smad2 (MilliporeSigma, clone A5S, catalog 04 -953), anti-p-Smad2/3 (Abcam, ab52903), anti-SMMHC (Abcam, ab53219), and anti-YFP (Abcam, ab13970). Images were acquired on a Zeiss 710NLO-Meta multiphoton confocal microscope or Zeiss LSM780-FCS confocal microscope at $\times 25$ magnification and are presented as maximal intensity projection. Image adjustments to enhance visualization of information present in the original were applied equally across samples. Sections stained with Masson's trichrome reagents were examined with a Nikon $80 \mathrm{i}$ using $\times 4$ and $\times 20$ objectives. Sections stained with Verhoeff-van Gieson stain were processed as described previously (19).

In situ analysis with RNAscope probes. Preparation of aortic tissue for RNA in situ hybridization with RNAscope probes from Advanced Cell Diagnostics was performed according to the manufacturer's instructions optimized for the Fixed/Frozen Tissue and RNAscope
Multiplex Fluorescent Reagent Kit (catalog 320850). The following probes were used: Mm-Agtr1a (C1 channel, catalog 481161), Mm-Tgfb1 (C3 channel, catalog 403451-C3), Mm-Tgfb3 (C1 channel, catalog 406211), and Mm-Myh11 (C2 channel, catalog 316101-C2). Images were acquired on a Zeiss LSM780-FCS confocal microscope at $\times 40$ magnification, and are presented as maximal intensity projection. Image adjustments to enhance visualization of information present in the original were equally applied across samples.

Generation of lineage-traced primary smooth muscle cell cultures. Aortic root and proximal ascending aortas were dissected at approximately 8 weeks of age. Both males and females were used to establish these cultures; the sex of samples used in each experiment is provided in Supplemental Table 1. To remove the adventitial layer, aortas were incubated in HBSS (Life Technologies) containing $300 \mathrm{U} /$ $\mathrm{ml}$ collagenase II (Worthington Biochemical Corp.) for 15 minutes at $37^{\circ} \mathrm{C}$. After this treatment, the adventitial layer was stripped by gentle pulling with tweezers, incubated with DMEM plus 10\% FBS, and used to establish cultures of adventitial fibroblasts without further processing. The aortic media tissue was incubated overnight in DMEM (Life Technologies) complete with antibiotics and $20 \%$ FBS, transferred to a new well, and then further digested with $300 \mathrm{U} / \mathrm{ml}$ collagenase II and $3 \mathrm{U} / \mathrm{ml}$ elastase for 45 minutes at $37^{\circ} \mathrm{C}$. A scalpel was then used to mince the remaining tissue and score the culture wells to facilitate adherence. Tissue was then incubated with DMEM plus 20\% FBS until confluent cultures of smooth muscle cells could be established, after which they were maintained in DMEM plus antibiotics and $10 \%$ FBS. SHF-traced and CNC-traced cells were sorted from these cultures based on Td-Tomato or YFP expression using a Becton Dickinson FACSAria sorter, which was operated by the Johns Hopkins University Ross Flow Cytometry Core Facility. All sorted lineage-traced VSMCs were analyzed by flow cytometry to confirm expression of lineage marker ( $\geq 95 \%$ positive) prior to in vitro experiments; all experiments were conducted using cultures between 3 and 9 passages from the time of sorting.

Stimulation and analysis of lineage-traced smooth muscle cells. Primary cultures were starved in DMEM containing no serum for at least 18 hours prior to stimulation with indicated ligands. Cells were stimulated with recombinant TGF- $\beta 1$ (Biolegend, catalog 580704), AngII (MilliporeSigma, catalog A9525), or vehicle. Identical protocols were used for stimulation of adventitial fibroblasts. For assessment of signaling events by immunoblot, stimulation was stopped by removing stimulation media, quickly washing with $1 \times$ PBS (Life Technologies), and then adding M-PER lysis buffer (Pierce) plus protease and phosphatase inhibitors (MilliporeSigma).

Stimulation and analysis of $T$ lymphocytes. Splenocytes were isolated by mechanical disruption from the spleen of control and mutant mice at 10 weeks of age. After lysis of red blood cells with ACK lysis buffer, splenocytes were rested overnight in IMDM supplemented with $0.1 \%$ FBS, penicillin/streptomycin, and $\beta$-mercaptoethanol. The next morning, splenocytes were stimulated with $0.5 \mathrm{ng} / \mathrm{ml}$ of TGF- $\beta$ (R\&D Systems, 240-B) for 30 minutes. Stimulation was ended by fixing the cells by direct addition of BD Lyse/Fix buffer (BD Biosciences, 558048). Cells were permeabilized with BD Perm III buffer (BD Biosciences, 558050) according to the manufacturer's instructions prior to staining for flow cytometry. Samples were stained with PE anti-Smad2 (pS465/pS467)/Smad3 (pS423/pS425) (BD Biosciences, 562586), BV605 anti-CD4 (BD Biosciences, 563151), AF700 anti- 
CD8 (eBioscience, 56-0081-82), and APCef780 anti-TCR- $\beta$ (eBioscience, 47-5961-82). Data were acquired using an LSR Fortessa (BD Biosciences) and analyzed using FlowJo software (Tree Star Inc.).

Stimulation and analysis of smooth muscle cells by flow cytometry. Flow cytometry data were acquired on a FACSVerse flow cytometer (BD Biosciences), and analyzed with FlowJo software. For quantification of bromodeoxyuridine (BrdU) incorporation, cells were starved in serum-free DMEM for 24 hours prior to exposure to normal culture media for 24 hours; cultures were pulsed with BrdU in the last 6 hours. The percentage of $\mathrm{BrdU}^{+}$cells was assayed with reagents and protocols from the APC BrdU Flow Kit (BD Biosciences, 552598). Intracellular staining for SMMHC was performed on cells growing under normal culture conditions, which were trypsinized, resuspended in BD Biosciences Perm/Wash Buffer (catalog 554723), and stained with anti-SMMHC antibody (Abcam, ab125884), followed by anti-rabbit secondary antibody conjugated to APC (Jackson ImmunoResearch, 711-136-152). The epithelial cell line NMuMG (CRL-1636) was obtained from ATCC and used as negative control for SMMHC expression. For assessment of Smad2/3 phosphorylation by flow cytometry, stimulation was stopped by removing stimulation media, quickly lifting the cells from the plate by flushing with 1 volume of $0.25 \%$ Trypsin-EDTA (GIBCO), and directly adding the cell suspension into a flow cytometry tube containing 1 volume of $8 \%$ PFA (Electron Microscopy Sciences) in PBS, for a final concentration of $4 \%$ PFA. Cells were fixed in $4 \%$ PFA at $37^{\circ} \mathrm{C}$ for 15 minutes, permeabilized in ice-cold $90 \%$ methanol for 30 minutes, and resuspended in flow cytometry buffer (PBS, 0.5\% BSA) for 30 minutes. Cells were probed with Alexa Fluor 647 anti-Smad2 (pS465/pS467)/Smad3 (pS423/pS425), clone O72670 , from BD Biosciences for 1 hour prior to analysis.

Echocardiography. Echocardiographic measurements of parasternal long-axis view were performed at the indicated time points using Visualsonics Vevo 2100 and a $30-\mathrm{MHz}$ probe on conscious mice, whose hair had been removed with Nair cream. Quantification of diameters was obtained by averaging 3 independent measurements of the maximal internal dimension at the sinus of Valsalva for aortic root measurements and at the proximal ascending aorta for ascending aorta measurements. A cardiologist blinded to genotype and treatment arm was responsible for all imaging and measurements. Growth was defined as the difference between aortic size at baseline (6 or 8 weeks of age, as noted in the figures) and the endpoint (20 or 24 weeks of age, as noted in the figures).

LCM. TdTomato-traced tissue was obtained from the aortic root of control or $\mathrm{Tbr} \mathrm{I}^{\mathrm{MR} / \mathrm{+}}$ mice that also carried the Mef $2 \mathrm{C}^{\mathrm{SHF}}-\mathrm{Cre}$; $\mathrm{R} 26 \mathrm{R}-\mathrm{Td}$ Tomato $^{+-}$or Wnt1-Cre2; R26R-TdTomato ${ }^{+/}$alleles. Mice were sacrificed at 3 months of age. Dissected hearts and thoracic aortas were flushed with PBS and flash-frozen using liquid nitrogen prior to being embedded and frozen in Tissue-Tek OCT compound. Sections $(8 \mu \mathrm{m})$ were cut in a longitudinal axis view to obtain the entire aortic root and placed onto glass PEN membrane slides (Leica, 11600288) and stored at $-80^{\circ} \mathrm{C}$. Immediately prior to LCM, slides were washed in distilled water for 30 seconds, followed by a gradient series of ethanol washes (75\% ethanol for 10 seconds, $90 \%$ ethanol for 20 seconds, and $100 \%$ ethanol for 3 minutes). Slides were air-dried and then kept on ice until LCM. TdTomato-traced tissue was microdissected from approximately 15 slides per aorta using a Leica LMD 7000 coupled with a xenon fluorescence bulb, which allowed for visualization of Td-Tomato-positive tissue without the need for additional staining. Microdissections were anatomically limited to tissue within aortic roots, and captured tissue fragments were binned into microcentrifuge tubes for RNA isolation.

RNA extraction. For assessment of RNA induction by qPCR in cultured cells, stimulation was stopped by removing stimulation media, and followed by direct lysis in TRIzol (Life Technologies). RNA was then extracted using chloroform and 70\% ethanol, followed by on-column DNAse digestion on RNeasy Mini columns (Qiagen) to remove any genomic DNA contamination. RNA extraction for samples obtained with LCM was performed using a PicoPure RNA Isolation Kit (Thermo Fisher Scientific) according to the manufacturer's instructions, also including an on-column DNAse digestion.

$R T-q P C R$ and quantification of transcript expression. Transcript levels for the gene of interest were determined using a High-Capacity cDNA Reverse Transcription Kit (Thermo Fisher Scientific) followed by qPCR using prevalidated TaqMan probes and TaqMan Universal PCR Master Mix reagents. A pre-amplification step using TaqMan PreAmp Master Mix was included for cDNA derived from samples obtained by LCM. Reactions were run and analyzed using a QuantStudio 7 Flex Real-Time PCR System (Thermo Fisher Scientific). The following prevalidated TaqMan probes were used to detect specific transcripts: Mm00446968_m1 (Hprt), Mm01178820_m1 (Tgfb1), Mm00436955_m1 (Tgfb2), Mm00436960_m1 (Tgfb3), Mm01166161_ m1 (Agtr1a), Mm00443013_m1 (Myh11), Mm00435860_m1 (Serpine1), Mm01192932_g1 (Ctgf), Mm00434339_m1 (Inhba), and Mm00487530_m1 (Smad2). A custom probe was designed by Applied Biosystems and validated to detect TdTomato transcripts (AIVI52M). Expression of the transcript of interest was normalized to that of the housekeeping gene Hprt using the $2^{\Delta \Delta \mathrm{CT}}$ method.

Statistics. Data are presented as scatter dot-plots with boxes, with each dot identifying a biological replicate; the box denotes the mean, and error bars identify the $95 \%$ confidence interval. At least 3 independent biological replicates (each derived from independent individuals) for each genotype and lineage-of-origin were used for each experiment shown; each experiment involving primary cell cultures was replicated at least twice. Experiments involving monitoring of aortic size in live animals and LCM were performed once. No formal randomization method was applied; all group allocations were made based on genotype with an effort to maintain a similar number of male and female individuals in each group. No other stratification criteria were applied. All echocardiograms were performed and interpreted by individuals blinded to genotype and treatment arm. The statistical test employed for each figure panel is described in the figure legend. Unless otherwise indicated, the nonparametric Kruskal-Wallis test was used for comparisons between groups. The 2-stage linear stepup procedure of Benjamini, Krieger, and Yekutieli was used to correct for multiple comparison by controlling the false discovery rate (FDR), with a family-wise significance and confidence level of $Q=0.05$. If parametric 1-way ANOVA was used, this was done only after the Shapiro-Wilk normality test validated assumption of normal distribution, and the Brown-Forsythe test that of equal variance; the Holm-Sidak test was used for post hoc multiple comparisons tests. Data sets subjected to the same family-wise statistical test (i.e., Kruskal-Wallis or 1-way ANOVA) but separate group-wise post hoc comparisons (i.e., Benjamini, Krieger, and Yekutieli FDR test or Holm-Sidak test) are separated by vertical lines if presented within one data display. A $P$ value $\leq 0.05$ was considered significant. All statistical analyses were performed with GraphPad Prism 7 software. 
Study approval. This study was performed in accordance with the recommendations in the NIH Guide for the Care and Use of Laboratory Animals (National Academies Press, 2011). All of the animals were handled according to approved institutional animal care and use committee (IACUC) protocols of the Johns Hopkins University School of Medicine. The protocol was approved by the Committee on the Ethics of Animal Experiments of the Johns Hopkins University School of Medicine.

\section{Author contributions}

HCD and EGM developed the concept. EGM designed, performed, and directed experiments, analyzed data, and wrote the manuscript. HCD, SGZ, and RB provided essential expertise in the editing of the manuscript. JPH and DB acquired, and JPH analyzed, all echocardiographic images. JYS optimized the conditions for laser capture microdissection and performed related experiments. SGZ, SJP, TJC, and JFC assisted in the execution and interpretation of in vitro experiments with primary cells. $\mathrm{RB}$ and $\mathrm{YC}$ provided essential technical assistance for mouse colony maintenance and tissue processing for histological and molecular analysis. MEL obtained and established critical mouse lines and techniques, and performed critical pilot experiments that contributed to the final experimental design. KW and PAFG conducted and analyzed experiments with control and mutant lymphocytes. All authors discussed the results and commented on the manuscript prior to submission.

\section{Acknowledgments}

This work was supported by the Howard Hughes Medical Institute, the Leducq Foundation, and by grants from the NIH (R01AR41135-18 to HCD and K99/R00-HL121287 to EGM). EGM was also supported by the Broccoli family and the Loeys-Dietz Foun- dation. This work was also supported, in part, by the Division of Intramural Research, NIH (to PAFG and KW). JFC was partially funded by Fondecyt grant 11170353 . We thank the members of the Dietz laboratory for helpful discussions. We thank the Johns Hopkins School of Medicine Microscope Core Facility for training and assistance in image acquisition (support provided by NIH grants S10 OD016374 and S10 RR024550) and The Sidney Kimmel Comprehensive Cancer Center Cell Imaging Core Facility for assistance with laser capture microdissection.

Address correspondence to: Hal C. Dietz, Johns Hopkins University School of Medicine, Broadway Research Building Room 539, 733 N. Broadway, Baltimore, Maryland 21205, USA. Phone: 410.614.0701; Email: hdietz@jhmi.edu.

SJP's present address is: Smidt Heart Institute, Department of Medicine and Biomedical Sciences, Cedars-Sinai Medical Center, Los Angeles, California, USA.

JFC's present address is: Centro de Genética y Genómica, Facultad de Medicina, Clínica Alemana Universidad del Desarrollo, Santiago, Chile.

MEL's present address is: Thoracic Aortic Center, Cardiology Division and Cardiovascular Research Center, Department of Medicine, Massachusetts General Hospital and Harvard Medical School, Boston, Massachusetts, USA.

BEK's present address is: Department of Human Genetics, School of Medicine, Emory University, Atlanta, Georgia, USA.
1. Goldfinger JZ, Halperin JL, Marin ML, Stewart AS, Eagle KA, Fuster V. Thoracic aortic aneurysm and dissection. J Am Coll Cardiol. 2014;64(16):1725-1739.

2. Verstraeten A, Luyckx I, Loeys B. Aetiology and management of hereditary aortopathy. Nat Rev Cardiol. 2017;14(4):197-208.

3. Lindsay ME, Dietz HC. Lessons on the pathogenesis of aneurysm from heritable conditions. Nature. 2011;473(7347):308-316.

4. Patel ND, et al. Aortic root replacement for children with Loeys-Dietz syndrome. Ann Thorac Surg. 2017;103(5):1513-1518.

5. Danyi P, Elefteriades JA, Jovin IS. Medical therapy of thoracic aortic aneurysms: are we there yet? Circulation. 2011;124(13):1469-1476.

6. MacCarrick G, et al. Loeys-Dietz syndrome: a primer for diagnosis and management. Genet Med. 2014;16(8):576-587.

7. Heldin $\mathrm{CH}$, Moustakas A. Signaling receptors for TGF- $\beta$ family members. Cold Spring Harb Perspect Biol. 2016;8(8):a022053.

8. Hata A, Chen YG. TGF- $\beta$ signaling from receptors to Smads. Cold Spring Harb Perspect Biol. 2016;8(9):a022061.

9. Budi EH, Duan D, Derynck R. Transforming growth factor- $\beta$ receptors and Smads: Regulatory complexity and functional versatility. Trends Cell Biol. 2017;27(9):658-672.

10. Derynck R, Zhang YE. Smad-dependent and
Smad-independent pathways in TGF-beta family signalling. Nature. 2003;425(6958):577-584.

11. Zhang YE. Non-Smad Signaling pathways of the TGF- $\beta$ family. Cold Spring Harb Perspect Biol. 2017;9(2):a022129.

12. Loeys BL, et al. A syndrome of altered cardiovascular, craniofacial, neurocognitive and skeletal development caused by mutations in TGFBR1 or TGFBR2. Nat Genet. 2005;37(3):275-281.

13. van de Laar IM, et al. Mutations in SMAD3 cause a syndromic form of aortic aneurysms and dissections with early-onset osteoarthritis. Nat Genet. 2011;43(2):121-126.

14. Lindsay ME, et al. Loss-of-function mutations in TGFB2 cause a syndromic presentation of thoracic aortic aneurysm. Nat Genet. 2012;44(8):922-927.

15. Wischmeijer A, et al. Thoracic aortic aneurysm in infancy in aneurysms-osteoarthritis syndrome due to a novel SMAD3 mutation: further delineation of the phenotype. Am JMed Genet A. 2013;161A(5):1028-1035.

16. Bertoli-Avella AM, et al. Mutations in a TGF- $\beta$ ligand, TGFB3, cause syndromic aortic aneurysms and dissections. J Am Coll Cardiol. 2015;65(13):1324-1336.

17. Micha D, et al. SMAD2 mutations are associated with arterial aneurysms and dissections. Hum Mutat. 2015;36(12):1145-1149.

18. Schepers D, et al. A mutation update on the
LDS-associated genes TGFB2/3 and SMAD2/3. Hum Mutat. 2018;39(5):621-634.

19. Gallo EM, et al. Angiotensin II-dependent TGF- $\beta$ signaling contributes to Loeys-Dietz syndrome vascular pathogenesis. JClin Invest. 2014;124(1):448-460

20. Loeys BL, et al. Aneurysm syndromes caused by mutations in the TGF-beta receptor. $N$ Engl J Med. 2006;355(8):788-798.

21. van der Pluijm I, et al. Defective connective tissue remodeling in Smad3 mice leads to accelerated aneurysmal growth through disturbed downstream TGF- $\beta$ signaling. EBioMedicine. 2016;12:280-294.

22. Chen X, Lu H, Rateri DL, Cassis LA, Daugherty A. Conundrum of angiotensin II and TGF- $\beta$ interactions in aortic aneurysms. Curr Opin Pharmacol. 2013;13(2):180-185.

23. Daugherty A, Chen Z, Sawada H, Rateri DL, Sheppard MB. Transforming growth factor- $\beta$ in thoracic aortic aneurysms: Good, bad, or irrelevant? J Am Heart Assoc. 2017;6(1):e005221.

24. Milewicz DM, Prakash SK, Ramirez F. Therapeutics targeting drivers of thoracic aortic aneurysms and acute aortic dissections: Insights from predisposing genes and mouse models. Annu Rev Med. 2017;68:51-67.

25. Topouzis S, Majesky MW. Smooth muscle lineage diversity in the chick embryo. Two types of aortic smooth muscle cell differ in growth and 
receptor-mediated transcriptional responses to transforming growth factor-beta. Dev Biol. 1996;178(2):430-445

26. Trigueros-Motos L, et al. Embryological-origin-dependent differences in homeobox expression in adult aorta: role in regional phenotypic variability and regulation of NF- $\kappa \mathrm{B}$ activity. Arterioscler Thromb Vasc Biol. 2013;33(6):1248-1256.

27. Sinha S, Iyer D, Granata A. Embryonic origins of human vascular smooth muscle cells: implications for in vitro modeling and clinical application. Cell Mol Life Sci. 2014;71(12):2271-2288.

28. Cheung C, Bernardo AS, Trotter MW, Pedersen RA, Sinha S. Generation of human vascular smooth muscle subtypes provides insight into embryological origin-dependent disease susceptibility. Nat Biotechnol. 2012;30(2):165-173.

29. Awgulewitsch A, Majesky MW. Interpreting inflammation: smooth muscle positional identity and nuclear factor- $\mathrm{kB}$ signaling. Arterioscler Thromb Vasc Biol. 2013;33(6):1113-1115.

30. Buckingham M, Meilhac S, Zaffran S. Building the mammalian heart from two sources of myocardial cells. Nat Rev Genet. 2005;6(11):826-835.

31. Vincent SD, Buckingham ME. How to make a heart: the origin and regulation of cardiac progenitor cells. Curr Top Dev Biol. 2010;90:1-41.

32. Huang $\mathrm{T}$, et al. TGF- $\beta$ signalling is mediated by two autonomously functioning T $\beta$ RI:T $\beta$ RII pairs. EMBO J. 2011;30(7):1263-1276.

33. Verzi MP, McCulley DJ, De Val S, Dodou E, Black $\mathrm{BL}$. The right ventricle, outflow tract, and ventricular septum comprise a restricted expression domain within the secondary/anterior heart field. Dev Biol. 2005;287(1):134-145.

34. Jiang X, Rowitch DH, Soriano P, McMahon AP, Sucov HM. Fate of the mammalian cardiac neural crest. Development. 2000;127(8):1607-1616.

35. Lewis AE, Vasudevan HN, O'Neill AK, Soriano P, Bush JO. The widely used Wnt1-Cre transgene causes developmental phenotypes by ectopic activation of Wnt signaling. Dev Biol. 2013;379(2):229-234.

36. Sawada H, Rateri DL, Moorleghen JJ, Majesky MW, Daugherty A. Smooth muscle cells derived from second heart field and cardiac neural crest reside in spatially distinct domains in the media of the ascending aorta-Brief Report. Arterioscler Thromb Vasc Biol. 2017;37(9):1722-1726.

37. Lamouille S, Derynck R. Cell size and invasion in TGF-beta-induced epithelial to mesenchymal transition is regulated by activation of the mTOR pathway. J Cell Biol. 2007;178(3):437-451.

38. Lee MK, et al. TGF-beta activates Erk MAP kinase signalling through direct phosphorylation of ShcA. EMBO J. 2007;26(17):3957-3967.

39. Eguchi S, Dempsey PJ, Frank GD, Motley ED, Inagami T. Activation of MAPKs by angiotensin II in vascular smooth muscle cells. Metalloproteasedependent EGF receptor activation is required for activation of ERK and p38 MAPK but not for JNK. JBiol Chem. 2001;276(11):7957-7962.

40. Gibbons GH, Pratt RE, Dzau VJ. Vascular smooth muscle cell hypertrophy vs. hyperplasia. Autocrine transforming growth factor-beta 1 expression determines growth response to angiotensin II. J Clin Invest. 1992;90(2):456-461.

41. Makanji Y, et al. Inhibin at 90: from discovery to clinical application, a historical review. Endocr Rev. 2014;35(5):747-794.

42. Pawlowski JE, et al. Stimulation of activin A expression in rat aortic smooth muscle cells by thrombin and angiotensin II correlates with neointimal formation in vivo. JClin Invest. 1997;100(3):639-648.

43. Gomez D, et al. Epigenetic control of vascular smooth muscle cells in Marfan and non-Marfan thoracic aortic aneurysms. Cardiovasc Res. 2011;89(2):446-456.

44. Ju W, et al. Deletion of Smad2 in mouse liver reveals novel functions in hepatocyte growth and differentiation. Mol Cell Biol. 2006;26(2):654-667.

45. Xie WB, et al. Smad2 and myocardin-related transcription factor $\mathrm{B}$ cooperatively regulate vascular smooth muscle differentiation from neural crest cells. Circ Res. 2013;113(8):e76-e86.

46. Schoenhoff FS. Increased TGF- $\beta$ signaling precedes aneurysm formation in SMAD3 deficient mice. EBioMedicine. 2016;12:26-27.

47. Neptune ER, et al. Dysregulation of TGF-beta activation contributes to pathogenesis in Marfan syndrome. Nat Genet. 2003;33(3):407-411.

48. Habashi JP, et al. Losartan, an AT1 antagonist, prevents aortic aneurysm in a mouse model of Marfan syndrome. Science. 2006;312(5770):117-121.

49. Carmignac V, et al. In-frame mutations in exon 1 of SKI cause dominant Shprintzen-Goldberg syndrome. Am J Hum Genet. 2012;91(5):950-957.

50 . Doyle AJ, et al. Mutations in the TGF- $\beta$ repressor SKI cause Shprintzen-Goldberg syndrome with aortic aneurysm. Nat Genet. 2012;44(11):1249-1254.

51. Meester JA, et al. Loss-of-function mutations in the X-linked biglycan gene cause a severe syndromic form of thoracic aortic aneurysms and dissections. Genet Med. 2017;19(4):386-395.

52. Huang J, et al. Fibulin-4 deficiency results in ascending aortic aneurysms: a potential link between abnormal smooth muscle cell phenotype and aneurysm progression. Circ Res. 2010;106(3):583-592.

53. Nataatmadja M, West J, Prabowo S, West M. Angiotensin II receptor antagonism reduces transforming growth factor beta and Smad signaling in thoracic aortic aneurysm. Ochsner J. 2013;13(1):42-48.

54. Te Riet L, et al. AT1-receptor blockade, but not renin inhibition, reduces aneurysm growth and cardiac failure in fibulin-4 mice. J Hypertens. 2016;34(4):654-665.

55. Renard M, et al. Novel MYH11 and ACTA2 mutations reveal a role for enhanced TGF $\beta$ signaling in FTAAD. Int J Cardiol. 2013;165(2):314-321.

56. Cook JR, et al. Dimorphic effects of transforming growth factor- $\beta$ signaling during aortic aneurysm progression in mice suggest a combinatorial therapy for Marfan syndrome. Arterioscler Thromb Vasc Biol. 2015;35(4):911-917.

57. Humphrey JD, Schwartz MA, Tellides G, Milewicz DM. Role of mechanotransduction in vascular biology: focus on thoracic aortic aneurysms and dissections. Circ Res. 2015;116(8):1448-1461.

58. Choudhary B, Zhou J, Li P, Thomas S, Kaartinen V, Sucov HM. Absence of TGFbeta signaling in embryonic vascular smooth muscle leads to reduced lysyl oxidase expression, impaired elastogenesis, and aneurysm. Genesis. 2009;47(2):115-121.
59. Wang Y, et al. TGF-beta activity protects against inflammatory aortic aneurysm progression and complications in angiotensin II-infused mice. JClin Invest. 2010;120(2):422-432.

60. Li W, et al. Tgfbr2 disruption in postnatal smooth muscle impairs aortic wall homeostasis. J Clin Invest. 2014;124(2):755-767.

61. $\mathrm{Hu} \mathrm{JH}$, et al. Postnatal deletion of the type II transforming growth factor- $\beta$ receptor in smooth muscle cells causes severe aortopathy in mice. Arterioscler Thromb Vasc Biol. 2015;35(12):2647-2656.

62. Chen $X$, et al. TGF- $\beta$ neutralization enhances AngII-induced aortic rupture and aneurysm in both thoracic and abdominal regions. PLoS One. 2016;11(4):e0153811.

63. Wei H, et al. Aortopathy in a mouse model of marfan syndrome is not mediated by altered transforming growth factor $\beta$ signaling. J Am Heart Assoc. 2017;6(1):e004968.

64. Angelov SN, Zhu J, Hu JH, Dichek DA. What's the skinny on elastin deficiency and supravalvular aortic stenosis? Arterioscler Thromb Vasc Biol. 2017;37(5):740-742.

65. Da Ros F, et al. Targeting interleukin-1 $\beta$ protects from aortic aneurysms induced by disrupted transforming growth factor $\beta$ signaling. Immunity. 2017;47(5):959-973.e9.

66. Isselbacher EM, Lino Cardenas CL, Lindsay ME. Hereditary influence in thoracic aortic aneurysm and dissection. Circulation. 2016;133(24):2516-2528.

67. Zou Y, et al. Mechanical stress activates angiotensin II type 1 receptor without the involvement of angiotensin II. Nat Cell Biol. 2004;6(6):499-506.

68. Mederos y Schnitzler M, et al. Gq-coupled receptors as mechanosensors mediating myogenic vasoconstriction. EMBO J. 2008;27(23):3092-3103.

69. Buscemi L, et al. The single-molecule mechanics of the latent TGF- $\beta 1$ complex. Curr Biol. 2011;21(24):2046-2054.

70. Klingberg F, et al. Prestress in the extracellular matrix sensitizes latent TGF- $\beta 1$ for activation. J Cell Biol. 2014;207(2):283-297.

71. Bellini C, Korneva A, Zilberberg L, Ramirez F, Rifkin DB, Humphrey JD. Differential ascending and descending aortic mechanics parallel aneurysmal propensity in a mouse model of Marfan syndrome. J Biomech. 2016;49(12):2383-2389.

72. Robertson IB, Rifkin DB. Regulation of the bioavailability of TGF- $\beta$ and TGF- $\beta$-related proteins. Cold Spring Harb Perspect Biol. 2016;8(6):a021907.

73. Ye P, et al. GM-CSF contributes to aortic aneurysms resulting from SMAD3 deficiency. J Clin Invest. 2013;123(5):2317-2331.

74. Habashi JP, et al. Angiotensin II type 2 receptor signaling attenuates aortic aneurysm in mice through ERK antagonism. Science. 2011;332(6027):361-365.

75. Holm TM, et al. Noncanonical TGF $\beta$ signaling contributes to aortic aneurysm progression in Marfan syndrome mice. Science. 2011;332(6027):358-361.

76. Koitabashi N, et al. Pivotal role of cardiomyocyte TGF- $\beta$ signaling in the murine pathological response to sustained pressure overload. JClin Invest. 2011;121(6):2301-2312.

77. Li DY, et al. Novel arterial pathology in mice and humans hemizygous for elastin. J Clin Invest. 
1998;102(10):1783-1787.

78. Urbán Z, et al. Connection between elastin haploinsufficiency and increased cell proliferation in patients with supravalvular aortic stenosis and Williams-Beuren syndrome. Am JHum Genet. 2002;71(1):30-44.

79. Chen S, Kulik M, Lechleider RJ. Smad proteins regulate transcriptional induction of the SM22alpha gene by TGF-beta. Nucleic Acids Res. 2003;31(4):1302-1310.

80. Qiu P, et al. Myocardin enhances Smad3mediated transforming growth factor-beta 1 signaling in a CArG box-independent manner: Smad-binding element is an important cis element for SM22alpha transcription in vivo. Circ Res. 2005;97(10):983-991.

81. Chung AW, Au Yeung K, Sandor GG, Judge DP, Dietz HC, van Breemen C. Loss of elastic fiber integrity and reduction of vascular smooth muscle contraction resulting from the upregulated activities of matrix metalloproteinase- 2 and -9 in the thoracic aortic aneurysm in Marfan syndrome. Circ Res. 2007;101(5):512-522.

82. Gomez D, et al. Syndromic and non-syndromic aneurysms of the human ascending aorta share activation of the Smad2 pathway. J Pathol. 2009;218(1):131-142.

83. Nistala H, Lee-Arteaga S, Siciliano G, Smaldone S, Ramirez F. Extracellular regulation of transforming growth factor beta and bone morphogenetic protein signaling in bone. Ann N Y Acad Sci. 2010;1192:253-256.

84. Nistala H, et al. Fibrillin- 1 and - 2 differentially modulate endogenous TGF- $\beta$ and BMP bioavailability during bone formation. J Cell Biol. 2010;190(6):1107-1121.
85. Bargehr J, et al. Embryological origin of human smooth muscle cells influences their ability to support endothelial network formation. Stem Cells Transl Med. 2016;5(7):946-959.

86. Kari FA, et al. Late complications and distal growth rates of Marfan aortas after proximal aortic repair. Eur J Cardiothorac Surg. 2013;44(1):163-171.

87. Groenink M, et al. Losartan reduces aortic dilatation rate in adults with Marfan syndrome: a randomized controlled trial. Eur Heart $J$. 2013;34(45):3491-3500.

88. Srinivas $\mathrm{S}$, et al. Cre reporter strains produced by targeted insertion of EYFP and ECFP into the ROSA26 locus. BMC Dev Biol. 2001;1:4.

89. Madisen L, et al. A robust and high-throughput Cre reporting and characterization system for the whole mouse brain. Nat Neurosci. 2010;13(1):133-140. 